\title{
UNMANNED AERIAL VEHICLES IN HYDROLOGY AND WATER MANAGEMENT -APPLICATIONS, CHALLENGES AND PERSPECTIVES
}

Bharat Sharma Acharya ${ }^{1 *}$, Mahendra Bhandari ${ }^{2}$, Filippo Bandini ${ }^{3}$, Alonso Pizarro ${ }^{4}$, Matthew Perks $^{5}$, Deepak Raj Joshi ${ }^{6}$, Sheng Wang ${ }^{7}$, Toby Dogwiler ${ }^{8}$, Ram L Ray ${ }^{9}$, Gehendra Kharel ${ }^{10}$, Sadikshya Sharma ${ }^{11}$

\footnotetext{
${ }^{1}$ Department of Mines, State of Oklahoma, 2915 N Classen Blvd., Oklahoma City, OK 73106, USA

${ }^{2}$ Texas A\&M AgriLife Research and Extension Center, Corpus Christi, TX, USA

${ }^{3}$ Department of Environmental Engineering, Technical University of Denmark, Bygning 115, 2800, Kgs. Lyngby, Denmark

${ }^{4}$ Escuela de Ingeniería en Obras Civiles, Universidad Diego Portales, Santiago 8370109, Chile

${ }^{5}$ The School of Geography, Politics and Sociology, Newcastle University, UK

${ }^{6}$ Department of Agronomy, Horticulture \& Plant Science, South Dakota State University, Brookings, SD 57006, USA

${ }^{7}$ Institute for Sustainability, Energy and Environment, University of Illinois at Urbana-Champaign, Urbana, IL 61801, USA

${ }^{8}$ Department of Geography, Geology and Planning, Missouri State University, Springfield, MO 65897, USA

${ }^{9}$ Prairie View A\&M University, TX 77446, USA

${ }^{10}$ Department of Environmental Sciences, Texas Christian University, TCU Box 298835, Fort Worth, TX 76129, USA

${ }^{11}$ Department of Ecosystem Science and Management, Pennsylvania State University, University Park, PA 16802, USA
}

\section{Correspondence}

Bharat Sharma Acharya, $\mathrm{PhD}$

Editor-Water, MDPI

Editor-Sustainability-MDPI

Associate Editor-Agronomy Journal, ASA, CSSA, SSSA

Department of Mines

ate of Oklahoma

2915 N Classen Blvd., Suite 213

Oklahoma City, OK 73106

Email: sharma.acharya@mines.ok.gov

This article has been accepted for publication and undergone full peer review but has not been through the copyediting, typesetting, pagination and proofreading process, which may lead to differences between this version and the Version of Record. Please cite this article as doi: 10.1029/2021WR029925. 


\section{Abbreviations:}

ADCPs $=$ Acoustic Doppler Current Profiles; AIS = Ambient Illumination Sensor; AR = Augmented Reality; $\mathrm{CHM}=$ Canopy Height Model; $\mathrm{CMOS}=$ Complementary Metal Oxide Semiconductor; DATTUTDUT $=$ Deriving Atmosphere Turbulent Transport Useful to Dummies Using Temperature; DEM = Digital Elevation Model; DTM = Digital Terrain Model; EC = Electrical Conductivity; EVI = Enhanced Vegetation Index; GCPs = Ground Calibration Panels; GNSS = Global Navigation Satellite System; GPP = Gross Primary Productivity; GPR = Ground Penetrating Radar; GPS = Global Positioning System; ICAO = International Civil Aviation Organization; IR = Infra-Red; KLT-IV = Kanade-Lucas Tomasi Image Velocimetry; LiDAR = Light Detection and Ranging; LSPIV = Large Scale Particle Image Velocimetry; LSPTV = Large-Scale Particle Tracking Velocimetry; LTER = Longterm Ecological Research Network; LWCI = Leaf Water Content Index; MDWI = Maximum Difference Water Index; MODIS = Moderate Resolution Imaging Spectroradiometer; MS = Multi-Spectral; MSI = Moisture Stress Index; NDII = Normalized Difference Infrared Index; NDRE =Normalized Difference Red-Edge Index; NDVI = Normalized Difference Vegetation Index; NDWI = Normalized Difference Water Index; NEON =National Ecological Observing Network; NIR = Near-Infrared; OSAVI = Optimized Soil Adjusted Vegetation Index; OTV = Optical Tracking Velocimetry; PPK = Post-Processing Kinematic; PIV = Particle Image Velocimetry; PTV = Particle Tracking Velocimetry; RDVI = Renormalized Difference Vegetation Index; RGB = Red, Green and Blue; RPAS = Remotely Piloted Aircraft System; RPV = Remotely Piloted Vehicle; RTK = Real-Time Kinematic; SAVI = Soil-Adjusted Vegetation Index; SfM = Structure-from-motion; SMAP = Soil Moisture Active and Passive; SSIV = Surface Structure Image Velocimetry; STIV = SpaceTime Image Velocimetry; SWAMP = Smart Water Management Platform; TIR = Thermal Infra-Red; TSI = Thermal Stress Index; UAS = Unmanned Aerial Systems; UAV = Unmanned Aerial Vehicle; USV = Unmanned Surface Vehicle; UVS = Unmanned Vehicle System; VTOL = Vertical Take-off and Landing; WDRVI = Wide Dynamic Range Vegetation Index; WSE = Water Surface Elevation

This article is protected by copyright. All rights reserved. 


\begin{abstract}
The hydrologic sciences and water resources management have long depended on a combination of in-situ measurements and remotely-sensed data for research and regulatory purposes. In-situ measurements are constrained in their spatial distribution by both logistics and costs. Satelliteand manned aircraft-based remote sensing provide spatially broad data, but often of a coarse resolution. Furthermore, all these data collection methods are often limited in their ability to respond to specific short-term events when the data and imagery could inform real-time assessment and decision-making, especially during and immediately after natural disasters. Researchers and regulators are increasingly using Unmanned Aerial Vehicles (UAVs) to fill these gaps in both spatial and temporal data resolution. UAVs are often more cost-effective than traditional remote sensing or in-situ data collection methodologies and the availability of new advancements in UAV design, power supply, payload capacity, and sensors has been driving rapid innovations in their use in the hydrological sciences. This in-depth review explores these UAV technologies and how they are being employed for on-demand and cost-effective characterization, monitoring, assessment, and modeling of soil and water resources. Our discussion addresses both key opportunities and challenges in surface water and groundwater studies, land-atmosphere interaction studies, water management in agriculture and forestry, ecosystem monitoring, and hydrological modeling.
\end{abstract}

Keywords: Environmental Monitoring, Hydrology, Hyperspectral Sensors, LiDAR, Modeling, Remote Sensing, Unmanned Aerial Vehicles

This article is protected by copyright. All rights reserved. 


\section{Introduction}

Global water withdrawal and usage have risen nearly six-fold since 1900 . Approximately $69 \%$ of water withdrawals are used in agriculture, $19 \%$ in industries, and 12\% for municipal purposes (FAO, 2020). Anthropogenic disturbances and climate change affect the water cycle, water supply and demand, and impose stress on the global water systems (Haddeland et al., 2014). As such, hydrologists, geologists, agronomists, soil scientists, and engineers need reliable tools to monitor and manage surface and groundwater resources, particularly in locations where traditional monitoring is inadequate.

Traditional water monitoring and measurement techniques are time-consuming, costly, and typify an inadequate and disproportionate spatial and temporal range. Over the past few decades, airplanes and satellites have been the chief source of remotely-sensed water resource data. However, the usefulness of these platforms is mainly restricted to the largest spatial scales. The low frequency of temporal sampling is dictated by logistical costs (aerial imagery) or tasking schedules (satellites) (Becker et al., 2009; Xue and Su, 2017). The dearth of finer resolution data and temporal inflexibility of these platforms precludes the possibility of on-demand data acquisition that is often necessary to capture the highly transient processes operating at fine spatial scales necessary for the planning and management of water resources (e.g., freshwater abstraction) and the assessment of hazards (e.g., flood extents). However, with recent advances in sensors, cameras, rechargeable batteries, and image processing tools and techniques (Chabot, 2018; Pajares, 2015), unmanned aerial vehicles (UAVs) now present a rapid, accurate, and costeffective approach to the on-demand study of water resources in complex settings at a much finer scale (Anderson and Gaston, 2013; Bhardwaj et al., 2016; Rakha and Gorodetsky, 2018; Sullivan, 2006).

This article is protected by copyright. All rights reserved. 
Unmanned aerial vehicles are used non-invasively to remotely sense, access, and evaluate the form and structure of features within river catchments, and hydrological processes across spatial and temporal scales. They integrate spatial, temporal, spectral, and continuous data to enable soil and water characterization and hydrological forecasting (Quiquerez et al., 2014; Woodget et al., 2017). UAVs acquire real-time in-situ water quality parameters primarily due to advances in robotics, sensor technologies, wireless networks, and image processing systems, and therefore to help improve the spatial resolution of remote sensing in water quality monitoring. For example, Becker et al. (2019) used a UAV-based spectroradiometer to study potential algal blooms in near-real-time in the Maumee River and the western basin of Lake Erie. Chabot (2018) posited three major advantages of modern-day UAVs compared with conventional radio-controlled hobby airplanes: (i) sophisticated auto-pilot systems integrating autonomous flight and userfriendly flight planning and tracking software, (ii) increased flight time due to advances in rechargeable battery technology, and (iii) lightweight, high-resolution and inexpensive compact digital cameras (discussed in later sections). Thus, UAVs have become a valued remote sensing platform due to flexible navigation, low maintenance, and operational cost, and reliability of results compared with traditional and intrusive techniques (Ridolfi and Manciola, 2018).

A rapid surge in UAVs usage to derive miscellaneous environmental information is globally documented. The US alone shows nearly 1.5 million UAVs and 160,000 remote pilots being registered by $5^{\text {th }}$ May 2020 (FAA, 2020). Research on the use of UAVs has been growing exponentially since 2015 (Chabot, 2018). Available reviews and studies have focused mainly on engineering (Chabot, 2018; Liu et al., 2014) and environmental applications (Eskandari et al., 2020; Manfreda et al., 2018). However, interests and advances in hydrology are on the rise. A few reviews are available within the hydrological science, but they emphasize single or a few

This article is protected by copyright. All rights reserved. 
selected hydrological variables. For examples, Kislik et al. (2018) and Wu et al. (2019) reviewed the application of UAVs in algal bloom research, Lally et al. (2019) reviewed the use of UAVs in water sampling, McDonald (2019) and Zakaria et al. (2018) reviewed the applicability of UAVs in urban stormwater management and flood monitoring, respectively while Rhee et al. (2017) focused on fluvial environments. More recently, Vélez-Nicolás et al. (2021) reviewed the application of UAVs in surface water and groundwater research. Despite these available reviews in hydrology, a clear, comprehensive, and one-stop review addressing different hydrological variables, sensors, and their applications is lacking. Thus, a comprehensive review of UAVs in this sector is important to identify current applications, developments, and challenges essential for water resource planning and management. This paper attempts to fill this gap by presenting an extensive review of more than 260 studies, focusing on the application of different UAVs and sensors in surface water and groundwater studies and water resource management. However, procedures and practices in data processing and visualization are not fully considered or discussed. Tools to derive UAV products are available from Thielicke et al. (2014), Perks (2020), and Le Coz et al. (2014), among others. Here, we first provide an overview of the UAV platforms (Section 3) before presenting information on different sensors and instruments, highlighting their general limitations (Section 4). Application of UAV sensors and review of studies related to different hydrological variables: rainfall, evaporation, overland flow, snow, soil moisture, surface water elevation, flow velocity, groundwater, water discharge, water quality, water storage, vegetation, land cover, and water vapor (McCabe et al., 2017) are categorized into four distinct but inter-related areas (a) surface hydrology and water management (Section 5), (b) subsurface hydrology and water management (Section 6), (c) land-atmosphere interactions (Section 7), and (d) other applications (ecosystem monitoring, modeling) (Section 8). Finally, we

This article is protected by copyright. All rights reserved. 
highlight the challenges (Section 9), opportunities, and prospects of using UAVs in hydrology (Section 10).

\section{LITERATURE SEARCH}

We conducted an exhaustive literature search in the Web of Science and Google Scholar database using key words "drones", "UAV”, "UVS”, “UAS”, "RPAS”, "RPV”, "unmanned aerial vehicle", "unmanned vehicle system", "unmanned aerial system", "remotely piloted aircraft system", "remotely piloted vehicle", and "structure from motion" alone and in combination with keywords "hydrology", "water quality", "surface water", "groundwater", “sensor”, "drainage”, “discharge”, “water velocity”, “velocimetry”, "bathymetry”, “water elevation", "soil moisture", "snow", “drought”, “flood”, “erosion”, “ponds", “agriculture”, "forest" "crop water status", "tile drainage", "evapotranspiration”, "ecosystem”, “model”, and "water management". Articles of interest had to be published within April 2021 and written in English. We manually screened relevant articles by reading the title and abstract and discarding duplicate papers to fit four previously mentioned areas. A total of 242 peer-reviewed articles and more than 20 conference papers, book chapters, and grey literature were selected and reviewed in detail for the basics, technical aspects, and application of UAVs.

\section{UAV Platforms}

Unmanned Aerial Vehicles are classified based on their weight, endurance, altitude, and operational radius (Table 1). UAV surveys require three major components: the data collection system (i.e., the aerial platform and sensors), data processing system (e.g., to generate surface

This article is protected by copyright. All rights reserved. 
models and orthomosaics), and data analysis (i.e., for visualization, extraction, and interpretation). UAV platforms are primarily classified based on their aerodynamic configuration, operational characteristics, and capabilities. In addition, UAVs may be differentiated according to size, cost, and payloads. Table 1 summarizes different types of UAV platforms used in hydrological studies, which are briefly discussed below.

Rotary-wing and fixed-wing UAV are the two most commonly used flight platforms in hydrology and water management studies. These platforms are shown in Fig. 1: A. DJI Matrice 100, a rotary-wing, and B. Fixed-wing customized UAV platform. Hydrological applications of rotary-wing UAV are available from Ahongshangbam et al. (2019), Capolupo et al. (2015), Resop et al. (2019), Wigmore et al. (2019), and Yang et al. (2019), whereas fixed-wing from De Michele et al. (2016), Templin et al. (2018), and Villanueva et al. (2019), among others. The choice of platform is a function of the study objectives and scope in relation to the necessary payload, flight ranges, maneuverability requirements, and similar considerations. Fixed-wing UAVs use wings to generate lift and control flight. They have longer endurance, greater payload capacity, and higher flight speed. In contrast, rotary-wing UAVs, which use multiple rotor blades to generate lift and control flight. By their nature, rotary-wing UAVs are highly maneuverable with vertical take-off and landing capacity. However, they have lower flight speeds and are more limited in flight altitude and duration because of the high-energy requirements of maintaining lift via the rotors. Quadcopters and hexacopters are the most common configuration of rotary-wing UAVs. In general, multi-rotor systems are preferred in hydrology due to their agility, maneuverability, and vertical take-off and landing capability (Jeziorska, 2019). Boon et al. (2017) compared fixed-wing and multi-rotor UAVs following similar sensor specifications, flight patterns, and altitude to derive Digital Terrain Models (DTMs) for environmental mapping. 
Multi-rotor UAVs were superior in spatial resolution, accuracy, precision, and object identification in the final derived analytical products. However, fixed-wing UAVs required less maintenance and ensured longer flight time.

The key components in both platforms include the frame, the navigation system, the power system, and the payload (Giordano et al., 2016). The frame holds all other components and may be constructed of polystyrene, plastic, aluminum, or carbon fiber, depending upon the type and model. A Global Navigation Satellite System (GNSS) antenna is attached to the frame to control the navigation system and collect location data. Manufacturers are increasingly integrating survey-grade GNSS systems into UAVs and related autopilot systems. Different systems are being deployed, but most UAVs use the post-processing kinematic (PPK) approach. However, several current UAVs can make real-time corrections using a Real-Time Kinematic (RTK) system (for example, DJI Phantom 4 RTK, SZ DJI Technology CO., Ltd, Shenzhen, China). PPK and RTK systems offer similar benefits. However, the PPK technique may be slightly more precise than RTK as the post-processing allows for applying Kalman filters in both backward (as in RTK) and forward directions (Cledat et al., 2020). In terms of in-field operations, a benefit of the PPK system is that it does not require a radio link between a base station and the rover (i.e., the UAV). However, RTK systems offer precise positioning data during the flight for better adherence to the flight plan and data collection targets and eliminate the necessity of postprocessing the positional data. Many UAV GNSS systems are capable of both PPK and RTK, which allows the user to choose the best option for a particular objective. Deploying, surveying, and retrieving ground control points (GCPs) are the most time- and labor-intensive aspects of UAV field operations. GCPs also add significantly to the time required to complete data 
processing after the acquisition of imagery. PPK and RTK techniques reduce dependency on GCPs for georeferencing of aerial imagery and other data products.

The power system consists of batteries required to supply power to motors and equipped sensors. Most UAVs use lithium polymer (LiPo) batteries, which have a very high-energy density and discharge rate ( $\mathrm{C}$ rate), and are lighter in weight. The payload includes any sensors or cameras attached or integrated into the system. Payload capacity is dependent on the frame size and weight of the other UAV components, the number of propellers, the power of each motor, and the battery type and capacity. While fixed-wing and multi-rotor aerial platforms are used in hydrology and water management, hybrid models are also increasingly being tested.

The hybrid models integrate different characteristics from both fixed-wing and multi-rotors. For example, several manufactures offer fixed-wing UAVs that can land vertically by spiraling to a controlled stall over the landing zone and then deploying a parachute to complete a vertical descent. A discussion of different miniature hybrid aerial models, their platform designs, dynamic modeling and control techniques, advantages, disadvantages, and challenges were presented in Saeed et al. (2018). Some hybrid models used in hydrology include hybrid unmanned aquatic-aerial quadcopter in Alzu'bi et al. (2018), Drews et al. (2014), and Ma et al. (2018), and quad-rotor fixed-wing hybrid UAVs in Kalpa Gunarathna and Munasinghe (2018). Generally, hybrid models can vertically takeoff like a multi-rotor UAV, navigate like a fixedwing UAV, cover a larger area at high speeds and altitudes, and land like a multi-rotor UAV. However, they are complex systems that demand a higher level of skill and training from the pilot.

This article is protected by copyright. All rights reserved. 


\section{Sensors and Instruments}

Table 2 lists different UAV sensors used in hydrology and water resources management with their advantages and disadvantages. Briefly, red, green, and blue (RGB) imaging sensors (Section 4.1), multi-spectral sensors (Section 4.2), hyperspectral sensors (Section 4.3), thermal sensors (Section 4.4), LiDAR sensors (Section 4.5), and microwave sensors (Section 4.6) were identified as commonly used UAV sensors in hydrological studies (Fig. 2). Sensors can be used alone or together, as illustrated in Fig. 3. Raw images obtained from UAV sensors are generally processed to generate orthomosaics and surface models. The process starts with uploading the raw images, followed by image alignment and georeferencing. In the latter step, the GPS coordinates of ground control points (GCPs) are uploaded in specific software to correct the geolocation of the images. After successful georeferencing, a 3d-dense point cloud is generated to develop geospatial data products. Digital Surface Model (DSM) is generated from the point clouds and orthomosaic image is developed from the surface model to further data analytics.

\subsection{RGB Sensors}

Table 3 presents some commonly used RGB imaging sensors (i.e., digital cameras). These sensors capture the reflectance observed in the visible spectrum $(400-700 \mathrm{~nm})$, and produce imagery with three values for individual red, green and blue pixels. While RGB cameras are available separately, they could be customized, if necessary, and mounted in the UAVs (Yao et al., 2019). Some UAVs such as the Phantom series and DJI Mavic series (SZ DJI Technology

CO., Ltd, Shenzhen, China), are available with integrated RGB sensors that are not designed by the manufacturer to be easily detached and swapped for alternative sensors. UAVs with RGB sensors are portable, easy to operate, relatively inexpensive, and provide high-quality RGB 
images for orthoimagery and the development of digital surface models (DSMs) (Yang et al., 2019) and orthomosaics (Beene et al., 2019; Templin et al., 2018). Some commercially available visible band cameras include Phase One, iXA 180, Trimble, IQ180, Hasselblad, H4D-60, NEX7, and GXR A16. Compared to other types of sensors, RGB cameras have a wider bandwidth, limited spectral resolution, and lack radiometric calibration options (Yao et al., 2019); the latter may, however, be attained using calibration panels (Bhandari et al., 2020). Key considerations when selecting an appropriate sensor include (i) the sensor size, with larger sensors generally resulting in higher quality images; (ii) the focal length, which determines the sensor's field-ofview, with short (e.g., 10mm) focal lengths being associated with high levels of geometric distortion; and (iii) the type of shutter employed, with global mechanical shutters offering faster shutter speeds than electronic rolling shutters, with the latter potentially inducing motion blur when the UAV is traveling at speed (e.g., $>4 \mathrm{~m} \mathrm{~s}^{-1}$; Vautherin et al. (2016).

\subsection{Multi-spectral Sensors}

Multi-spectral (MS) sensors generally capture the reflectance in the visible and near-infrared (NIR) region (between 400nm-1000nm). These sensors have a narrower bandwidth compared to RGB sensors. However, like RGB sensors, MS sensors may be predisposed to varying geometric distortions, dependent on the lens characteristics. Spectral and radiometric distortions (i.e., sample noise) should also be considered. MS sensors often come with radiometric calibration systems such as a calibration panel included with the MicaSense RedEdge sensor (MicaSense Inc., Seattle, US) and an Ambient Illumination Sensor (AIS) included with the SlantRange 3p sensor (SlantRange, Inc., California, US). Nonetheless, additional processing is often essential to perform radiometric corrections in the collected data; for example, to correct for the presence of 
aerosols that cause atmospheric scattering of the acquired signal (Amigo and Santos, 2020). MS image processing is relatively complex compared with RGB image processing and is more prone to issues related to data format compatibility (Yao et al., 2019). Also, MS sensors are relatively expensive, heavy, and can produce images with coarse pixel resolutions than RGB images. MS sensors usually come separately from UAVs and may need to be integrated into the system with after-market brackets or accessories. However, some UAV manufacturing companies have released UAVs with integrated MS sensors. One example is the Phantom 4 multi-spectral imaging drone (SZ DJI Technology CO., Ltd, Shenzhen, China). Different MS sensors and their specifications are presented in Table 4. The details on different cameras, their resolution, size, weight, spectral range, and sensitivity are also available from Colomina and Molina (2014).

\subsection{Hyperspectral Sensors}

Hyperspectral sensors have very high spectral resolutions capable of collecting reflectance in many narrow (5-10nm) and continuous bands covering a wide spectral range (350-13,400 nm)

(Table 5). Hyperspectral sensors provide greater spectral detail than MS sensors due to the ability to catch the visible, NIR, IR, TIR regions at a single-pixel (Colomina and Molina, 2014).

Because reflectances in the $1450 \mathrm{~nm}, 1900 \mathrm{~nm}$, and $2500 \mathrm{~nm}$ wavelengths are highly sensitive to atmospheric water, data acquisition with hyperspectral sensors should be piloted with caution under high humidity conditions. UAVs provide a unique opportunity to rapidly retrieve hyperspectral images at relatively lower costs for hydrological monitoring and modeling than satellites and pilot-operated airborne systems. Indeed, satellite-based hyperspectral sensing is expensive and time-consuming due to interferences from surface glints, reflection, refraction, and heterogeneous media (Zhang et al., 2020). However, hyperspectral sensors are expensive 
than multispectral sensors (Manfreda et al., 2018). Further, they have a lower spatial resolution and limited compatibility with standard UAV and flight control software packages. A few commercially available hyperspectral sensors include Micro-Hyperspec X-series NIR, Rikola Hyperspectral camera, Cubert FireflEYE, and HySpex Mjolnir.

\subsection{Thermal Sensors}

Every object on the Earth's surface emits radiation in the far-infrared region of the spectrum (3$100 \mu \mathrm{m})$, and the intensity of this radiation is a function of its surface temperature. A thermal camera acquires an image by collecting infrared radiation. Thermal sensors usually operate in the long-wave spectral bands (e.g., 7.5 - $13.5 \mu \mathrm{m}$ ), can sense a wide range of temperatures (e.g., -25 to $135^{\circ} \mathrm{C}$ ), and have a pixel sensitivity of as little as $0.04{ }^{\circ} \mathrm{C}$. However, they have a relatively low spatial resolution (with UAV compatible sensors currently having a maximum resolution of 640 x 512 pixels). UAV-mounted infrared sensors are also generally uncooled, which is beneficial due to their small size, and lightweight nature. However, these are also less thermally sensitive, and respond more slowly than cooled sensors to changes in temperature. Uncooled thermal sensors may exhibit thermal drift throughout a flight, as the camera's body either warms or cools. Significant fisheye effects are also observed with FLIR radiometric UAV cameras in which the center of an image appears warmer than the edges. When sensing scenes with transient energy signals or from a moving platform (e.g., UAVs), it may take time for change to be detected by the sensor. For quantitative assessments, images also need to be radiometrically calibrated (Pajares, 2015). Examples of commercially available thermal cameras are the FLIR, TAU 2 640, and Miricle 307K-25, and more details about specific thermal sensors and their specifications are available in Table 6.

This article is protected by copyright. All rights reserved. 


\subsection{LiDAR Sensors}

LiDAR is an active sensor that uses electromagnetic waves in optical and infrared wavelengths. Sensors operating in the infrared wavelength are broadly used for acquiring 3-D positional data describing earth topography and vegetation canopy height. Sensors operating in the green wavelength range are often referred to as bathymetric LiDAR, and can penetrate beneath the surface of waterbodies (Bagheri et al., 2015). High-frequency laser pulses are emitted from the sensor, and providing that the signal is not attenuated, the signal is returned to the sensor. The time taken for the signals to be returned is used to measure the distance between the targets and the sensor. A single pulse is typically reflected off multiple targets and yields multiple returns, which can be classified and used for different purposes. The last return is inferred to be the "bare earth" signal and is used for creating digital terrain models.

Some commonly used LiDAR sensors with their specifications are shown in Table 7. LiDAR can be differentiated between discrete return and full waveform systems (Anderson et al. 2016). Upon correction for sensor motion (typically achieved using a precise GNSS device and IMU unit), LiDAR sensors generate dense point clouds containing information about the elevation and intensity of point returns (typically discrete return system can provide only two returns, canopy and land, whilst full waveform systems can provide multiple returns), which may be used to generate terrain, and canopy height models.

However, Muhadi et al. (2020) reported problems in classification between ground and nonground surfaces under the LiDAR system. Additionally, the cost of the sensors and complexities in data processing and storage has reduced its popularity compared with photogrammetry. Structure-from-Motion (SfM) photogrammetry provides a method of acquiring point clouds at similar point densities and accuracies and using less expensive and lighter weight RGB cameras, 
but typically requires GCPs. Yet, employing more sophisticated ground filtering algorithms or integrating LiDAR data with other sensors (e.g., multi-spectral sensor) could benefit some hydrologic applications and improve data acquisition and classification of diverse objects.

\subsection{Microwave Sensors}

Microwave sensing encompasses both passive and active sensors. In passive microwave sensing, the natural thermal emission of the land surface (or brightness temperature) is measured with a radiometer at microwave wavelengths. Passive microwave methods allow for estimation of the surface reflectivity, which, according to Fresnel equations, is a function of the dielectric constant, viewing angle, and polarization. Since dielectric constants of water $(\sim 80)$ and soil particles ( 6) differ, soil water content affects brightness temperature measured at microwave wavelengths.

Several satellites have passive microwave sensors, such as the ESA's Soil Moisture and Ocean Salinity (SMOS) and NASA's Soil Moisture Active Passive (SMAP) missions (Champagne et al., 2016; Neill et al., 2010; Polcher et al., 2016). These satellites have a spatial resolution of a few $\mathrm{km}$ (from $\sim 50 \mathrm{~km}$ to $\sim 0.5 \mathrm{~km}$ ). Compared to satellites, UAV sensors can achieve significantly higher spatial resolution and are not affected by atmospheric interaction (Golubkov et al., 2018) and atmospheric transmittance, which becomes a critical factor, especially at high frequencies (>18 GHz) (Shi et al., 2015). GNSS-reflectometry falls in the category of passive low-frequency radar and measures Earth reflection of GNSS signal (Acevo-Herrera et al., 2009; Acevo-Herrera et al., 2010; Alonso-Arroyo et al., 2014; Dai et al., 2020; Houtz et al., 2020; Troglia Gamba et al., 2015).

This article is protected by copyright. All rights reserved. 
Active microwave sensors emit their microwave radiation; thus, they are not dependent on Earth's thermal properties or Earth's reflection of microwave radiation from the sun or other sources. Ground Penetrating Radar (GPR) is an n active sensor that emits high-frequency waves, typically in the range of $10 \mathrm{MHz}$ to $2.6 \mathrm{GHz}$ (radiation below $300 \mathrm{MHz}$ is generally classified as radio waves instead of microwave). GPR typically requires UAVs to be flown at low flight altitudes (typically a few meters above the surface). Examples of microwave sensors are provided in Table 8 .

\section{Surface Hydrology and Water Management}

In this section, we examine and discuss the application of a range of UAV mounted sensors for monitoring the water level and bathymetry of water systems (Section 5.1 - 5.2); determining surface water velocity and discharge (Section 5.3); water sampling (Section 5.4); mapping the depth and distribution of snow and ice (Section 5.5); assessing the impact of climate and vegetation on natural hazards and extreme events (Section 5.6), and water management in agriculture and forestry (Section 5.7). Additional deployments that are not discussed in detail within this section include thermal mapping (Dugdale et al., 2019), and monitoring and mapping wetlands (Becker et al., 2019; Jeziorska, 2019) and mining areas (Acharya and Kharel, 2020; Banerjee et al., 2020; Jackisch et al., 2018).

\subsection{Water Surface Elevation}

Water surface elevation (WSE) or the water level is typically referred to as the water surface elevation above the geoid (i.e., mean sea level). Typically, UAV-borne WSE measurements require observations from an accurate GNSS system, measuring the UAV-altitude above the

This article is protected by copyright. All rights reserved. 
ellipsoid and a ranging sensor measuring the range between the UAV and the water surface. Elevation above ellipsoid can be converted into elevation above the geoid based on the known geoid undulation. Then WSE can be computed as the difference between the UAV-borne altitude above the geoid and the range to the water surface. The WSE is an important component for flood prediction, mitigation, and forecasting.

Researchers have tried to use multiple sensors and techniques for measuring WSE: LiDAR, laser distance meters, photogrammetry, and radar. Guenther et al. (2000) discouraged using the green LiDAR as ranging sensors for WSE; indeed, green LiDAR returns from the water surface include three signal components or waveforms: reflections from the air-water interface, the volume backscatter returns, and the bottom returns of the waterbody. On the other hand, in NIR frequency, water surface absorption prevails on reflection; however, NIR LiDAR systems equipped with a laser of sufficient power, pulse width, and repetition can potentially be used on UAVs to measure the range to the water surface. Mandlburger et al. (2016) tested a green topobathymetric LiDAR (RIEGLBDF-1) and a NIR LiDAR (RIEGL VUX1-UAV) to detect river WSE (and bathymetry). Huang et al. (2018b) tested a lightweight and relatively low-cost laser (UTM-30LX, Hokuyo Automatic Co., LTD., Japan) on-board a UAV to measure WSE of the sea, including wave heights, demonstrating that the sensor could detect $10-35 \%$ of useful data returning from the pulse from a height of $6 \mathrm{~m}$ over the sea. Note that the maximum detection range is approximately $30 \mathrm{~m}$. However, the laser could receive $80-90 \%$ useful data returns if measurements are taken at $20 \mathrm{~m}$ height over the land surface.

Due to the weight and cost of UAV-borne LiDAR systems, researchers have attempted to deploy SfM photogrammetry using UAV-acquired imagery to measure WSE. However, despite the accuracy of UAV-borne photogrammetry in creating DEMs of solid surfaces, SfM algorithms 
are not effective in reconstructing WSE because of shadows, lack of stable visual key points on the water surface due to waves, and through-water penetration of visible light (Mohamad et al., 2019; Pingel et al., 2021). Westaway (2001) and Westaway et al. (2000) suggested that WSE profiles could be estimated by interpolating elevation measurements acquired from streambank locations ("water-edge") adjacent to the waterbody. Using "water-edge" points, Woodget et al. (2015) proved that WSE could be estimated with this method using UAV platforms. However, "water-edge" points can be successfully determined only if the streambanks exhibit clearly identifiable edges (e.g., vegetation/grass are not covering the streambanks) and shallow bank slopes (Javernick et al., 2014; Pai et al., 2017). Pai et al. (2017) also experimented with multispectral images to identify the water-edge points of a meandering river. Ridolfi and Manciola (2018) used UAV-photogrammetry to detect the "water-edge" between the water surface and the solid surface constituting a dam by applying Canny detection algorithms. Pingel et al. (2021) used SfM, combined with GCPs acquired with RTK-GPS, to estimate WSE in the Yucatan peninsula's cenotes by analyzing the histogram of the UAV imagery to remove reflections from vegetation and underwater features. GNSS-reflectometry has also been used to monitor water levels, such as in the sea, with a cm-accuracy in determining sea level after temporal averaging (Ichikawa et al., 2019). Bandini et al. (2018a) compared different ranging sensors, including a sonar system, a radar, and a laser-camera prototype in inland water bodies of Yucatan Peninsula, Mexico. The radar provided the best results and ensured the lowest processing time, as recently shown in Bandini et al. (2020), where a new $77 \mathrm{GHz}$ radar with full waveform analysis provided significantly more accurate results than photogrammetry or LiDAR, combined with a shorter surveying and processing time. Radar with full waveform output can provide a significant advantage in separating between water and surrounding targets (e.g., soil or

This article is protected by copyright. All rights reserved. 
vegetation). Indeed, high reflectivity from the water in the microwave spectrum ensures high return power when the water surface reflects the beam.

\subsection{Bathymetry}

Extracting information about the subsurface morphology of waterbodies (i.e., conducting bathymetric measurements) is vital to coastal modeling of storm surges, sea-level change and subsidence, and monitoring sediment transport and instream habitats. Bathymetric measurements are typically achieved with ultrasonic sensors mounted on manned vessels or unmanned surface vehicles (i.e., “drone ships” or USVs) (Erena et al., 2019; Giordano et al., 2016; Kum et al., 2020; Liang et al., 2017; Specht et al., 2020). Melcher et al. (2002) demonstrated the use of microwave/GPR systems to measure bathymetry in frozen waterbodies or low electric conductivity (e.g., smaller than $500 \mu \mathrm{S} / \mathrm{cm}$ ) freshwater with a manned helicopter. However, bathymetric observations using UAVs are typically based on (i) DEM generation through SfM techniques from through-water pictures, typically correcting for the refractive index of water (Bagheri et al., 2015; Brodie et al., 2019; Casella et al., 2017; Dietrich, 2017; Tamminga et al., 2015; Woodget et al., 2015), or (ii) spectral signature-depth correlation based on imagery retrieved with a multispectral or hyperspectral camera (Brodie et al., 2019; Flener et al., 2013; Lejot et al., 2007). To be successful, SfM methods typically require a texturized bottom and low water turbidity as well as the absence of sun glint and water ripples; whilst spectral methods typically require a uniform (and reasonably low) water turbidity and bottom. A fusion between SfM and spectral methods has also been proposed for seamless mapping of littoral zones (Starek and Giessel, 2017).

Researchers have also experimented with inferring bathymetry from observable features in coastal regions, such as surface wave kinematics (wavelength and frequency) or surface currents 
(Bergsma et al., 2019; Holland et al., 2010; Holman et al., 2011; Sun et al., 2019). Furthermore, a technique named fluid lens, a remote sensing method based on water-transmitting wavelengths able to detect bathymetry by exploiting time-varying optical lensing events caused by surface waves, has been applied to UAV imagery in coastal areas (Chirayath and Earle, 2016).

Novel instruments to acquire bathymetry data are lightweight green bathymetric LiDAR: i) the Riegl BDF-1 (Mandlburger et al., 2016), ii) the topo-bathymetric full-waveform green laser scanner Riegl VQ-840-G (Mandlburger et al., 2020), iii) the green scanner ASTRALiTe Edge Lidar (Kinzel and Legleiter, 2019), and iv) the green scanner TDOT green (Amuse Oneself Inc, Japan). These green LiDAR instruments can retrieve measurements of up to 1-1.5 times the Secchi depth; thus, they are only suitable for shallow water bodies or coastal areas with clear water. Furthermore, these LiDAR systems are expensive (typically more than 150000 USD) and typically weigh more than $5 \mathrm{~kg}$, and, thus, require large UAVs to be deployed. New operational methods to estimate river bathymetry in deep and turbid rivers need to be assessed to overcome these limitations. In this regard, Bandini et al. (2018a, b) and Alvarez et al. (2018) developed a new solution based on a sonar, which is kept in contact with the water surface, but tethered and controlled by the UAV. A similar tethered sonar solution has been recently commercialized by UgCS (UgCS, SPH Engineering, Latvia) and by Thurn Group (UK).

\subsection{Surface Water Velocity \& Discharge}

Streamflow monitoring is an essential part of hydrology, contributing to water resources policy and management, hydraulic construction design, and development and improvement of models (Blöschl et al., 2019; Manfreda et al., 2018). The standard monitoring framework for streamflow monitoring makes the use of flow meters or acoustic Doppler current profiles (ADCPs) (Bjerklie et al., 2020; Despax et al., 2019; Yorke and Oberg, 2002). Although these devices are currently 
considered the gold standard for streamflow measurements, they have many drawbacks. Chief among them is that automated monitoring is costly in terms of acquiring and installing the necessary equipment at each station, and manual measurements are time consuming and laborintensive. In addition, the need for specialized training, limitations with accessing and measuring remote locations, and human and equipment safety during high flows further compound the downsides of these standard methodologies (Tauro et al., 2018). UAV-based streamflow measurements could address many of these issues through non-contact gauging approaches utilizing UAV sensors or imagery (Eltner et al., 2020; Kinzel and Legleiter, 2019; Perks et al., 2016; Tauro et al., 2015). Image-based velocimetry in rivers provides a competent and noninvasive technique for surface flow velocity. These approaches are starting to become accepted as a standard operational practice by some regulatory authorities (e.g., Australian Government, US Geological Survey) (Australian Government Bureau of Meteorology, 2020; Kinzel and Legleiter, 2019; Legleiter et al., 2017; Legleiter and Kinzel, 2020).

Radar systems, exploiting the Doppler Effect, can be deployed to measure water surface velocity, as described by Plant et al. (2005) and more recently by Alimenti et al. (2020), who hypothesized future UAV-based adaptations. The capability to deploy a surface velocity radar from a mobile platform was demonstrated by Melcher et al. (2002), who deployed a surface velocity sensor onboard a manned helicopter. However, UAV-borne vibrations are significantly higher compared to manned helicopters and complicate UAV-based deployment.

Optical monitoring can estimate the spatial distribution of surface flow velocities through the analysis of remotely acquired videos, typically with RGB cameras, but, when natural light is not sufficient, also in the infrared spectrum (Dugan et al., 2013; Kinzel and Legleiter, 2019; Tauro and Grimaldi, 2017). Large Scale Particle Image Velocimetry (LSPIV) is particularly popular 
among optical approaches to process image sequences to estimate surface flow velocities in rivers (Fujita et al., 1998; Pearce et al., 2020; Tauro and Salvatori, 2017). The LSPIV grounds can explain this popularity in well-documented laboratory-based fluid mechanics researches (also known as Particle Image Velocimetry - PIV - in these conditions) and by the growing community providing open-source software and practice in general (Raffel et al., 2018; Thielicke and Stamhuis, 2014). Nevertheless, many different algorithms are currently used for surface flow velocity calculations. Among them, Large-Scale Particle Tracking Velocimetry (LSPTV) (Koutalakis et al., 2019), Surface Structure Image Velocimetry (SSIV) (Leitão et al., 2018), Optical Tracking Velocimetry (OTV) (Tauro et al., 2018), Kanade-Lucas Tomasi Image Velocimetry (KLT-IV) (Perks, 2020), and Space-Time Image Velocimetry (STIV) (Fujita et al., 1998). Pearce et al. (2020) applied five different image velocimetry algorithms (LSPIV, LSPTV, KLT-IV, OTV, and SSIV) on one field case study during low flow conditions to explore their sensitivity to feature extraction rate and particle identification area parameters. The authors found that all the five algorithms were comparable with measurements performed with standard streamflow measurements using velocity meters and ADCPs. Indeed, and on average, they were within $0.05 \mathrm{~m} / \mathrm{s}$ of the measurements. Worthy mentioning, LSPIV, LSPTV, and OTV required more effort for the right selection of appropriate parameters. At the same time, KLT-IV and SSIV presented a more automatized workflow, useful for experienced and non-experienced users. Recent advances in image-based gauging show a trend to find the optimal parameter setup within image velocimetry algorithms, minimizing the uncertainty and improving accuracy. Critical variables are the camera frame rate, tracer's properties such as seeding density and their spatial distribution, and the total number of frames to be analyzed. Due to the lack of available data (see, however, Perks et al. (2020) for a collection of datasets aiming at image-velocimetry 
analyses), several authors embraced numerical simulations to generate realistic configurations synthetically. Dal Sasso et al. (2018) used numerical simulations to explore the influence on PTV of seeding density, particle displacement (and consequently, frame rate), and the total number of frames under analysis. Results show that a correct frame rate is essential for realistic results, while high seeding density and the suitable spatial distribution of tracers support good velocity estimates. Investigating the effects of seeding characteristics on PTV and PIV, Dal Sasso et al. (2020) showed that temporal dynamics of seeding density, coefficient of variation of tracers' area, and spatial distribution have statistical significance on image-based performances. Furthermore, Pizarro et al. (2020a, b) introduced the dimensionless Seeding Distribution Index (SDI), which relies on the seeding density and spatial distribution of tracers. Remarkably, it was observed that lower values of SDI systematically produce a reduction in image-based velocity errors, leading to defining an optimal frame window (i.e., a portion of footage). Preliminary results showed a significant error reduction when the optimal frame window is used.

Data acquisition using UAVs, for example, velocimetry, could be performed in near to real-time. UAV-based data products are generated within a broad timing range, and depending on the specific workflow; this data generation time could vary from few seconds to hours and days (see e.g., Tosi et al. (2012) for in-situ and near real-time image velocimetry processing taking seconds to compute velocities in rivers). Pre-processing, processing, and post-processing phases are usually performed later in a processing center (see, e.g., Dal Sasso et al. (2021) or Paruta et al. (2020)), not at the moment of data acquisition. However, recent attempts - incorporating processing units' in-situ - are changing this modus operandis with views to real-time computations. Indeed, this appears to be the future for UAV-based data generation in all fields but depending on the variable to be measured; the latter will arrive sooner or later. Producing

This article is protected by copyright. All rights reserved. 
strong operational guidelines - minimizing computation times at the same time- must be the goal to be embraced by researchers and practitioners.

The surface velocity field can be converted into discharge if additional information about i) the river cross-section bathymetry and ii) the relationship between depth-averaged velocity and surface velocity. Depth-averaged velocity is generally estimated from the surface velocity by applying site-specific coefficients, typically on the order of 0.5-1.0 (Genç et al., 2015; Le Coz et al., 2010; Stumpf et al., 2016; Welber et al., 2016). An alternative approach has been proposed by Bandini et al. (2020), in which, if the uniform flow can be assumed, both discharge and Manning's roughness coefficient can be estimated from UAV-based measurements of water surface velocity and water surface slope, without requiring estimation of site-specific parameters. However, these approaches are based on the assumption that the velocity follows a log-law or at least a monotonic function; this is not always the case, and it becomes a weak assumption in the presence of secondary currents or dip phenomenon. An alternative approach is based on the method developed by Chiu (1991), based on the probabilistic principle of maximum entropy, which demonstrated that the $2 \mathrm{D}$ velocity distribution in a channel cross-section could be determined as a function of the maximum velocity and the curvilinear coordinates in the physical space. In this entropy approach, the main parameter is the entropic parameter, which is typically site-specific but is independent of flow conditions (Moramarco et al., 2019; Moramarco and Singh, 2010), while the other main parameter, named dip, can be estimated by an empirical relationship based on depth and distance from sidewalls (Yang et al., 2004). The river flows computed with these different methods are in good agreement with standard measurements, typically presenting errors less than 20-30\%, both from in-situ gauging stations (Dramais et al.,

This article is protected by copyright. All rights reserved. 
2011; Huang et al., 2018a; Kim et al., 2008; Le Coz et al., 2010) and UAVs (Bandini et al., 2020; Kinzel and Legleiter, 2019; Lewis et al., 2018).

\subsection{Hydro-Chemical Data Collection}

Hyperspectral sensors have been used in monitoring nitrogen, phosphorus, biological oxygen demand, chemical oxygen demand, total suspended solid, turbidity, chlorophyll-a content, and plastic floats in water (Rostom et al., 2017; Zhang et al., 2020). For example, Kwon et al. (2020) used UAV-based hyperspectral sensing to study cyanobacterial pigments in a deep artificial reservoir, South Korea. Similarly, Wei et al. (2019) used UAV-borne hyperspectral images to study suspended solid concentration in Beigong reservoir and Shahu Port riverway, China. Balsi et al. (2021) used a pushbroom hyperspectral sensor mounted on DJI Matrice 600 UAV to monitor sea and coastal macroplastic loading in Sardinia, Italy. Hydro-chemical data collection and water sampling have been made possible with new developments in complex water sampling payloads such as chassis-spring-lidded chambers with tubes, micro-pumps, thief-style samplers, HydraSleeves, Niskin water bottles, and multi-meter probes (Lally et al., 2019). The payloads could collect water samples ranging from $60 \mathrm{ml}$ (e.g., custom-built chassis-spring-lidded chambers) to $2 \mathrm{~L}$ (e.g., Niskin water bottle) within $40 \mathrm{~min}$ to 2 hours of total sampling time at success rates varying from 60 to 100\% (Lally et al., 2020). Key constraints to successful sampling using payloads such as chassis-spring-lidded chambers include faulty lids, improper pumps priming, pumps silt intake, and wind speed $>2.7 \mathrm{~m} / \mathrm{s}$. Further, the payloads must be waterproof and buoyant, and any contamination of water samples from built-in materials should be avoided (Lally et al., 2020). Castendyk et al. (2019) developed a Matrice-HydraSleeve method that uses surface water collecting cone connected to a UAV and illustrated its use in collecting water samples from a targeted depth of Dillon Reservoir in Colorado, US, and

This article is protected by copyright. All rights reserved. 
Thompson Creek Mine Pit Lake in Idaho, US. While this sampling approach is reported as a rapid, safe, and cost-effective method, it may have limited use under windy, rainy, and cloudy weather conditions. More details on the specification of different drone platforms (platform type, flight time, and communication software) and payloads for hydro-chemical water sampling and their general limitations were presented in Lally et al. (2020).

\subsection{Snow and Ice: Depth and Distribution}

Snow and ice accumulation and ablation are critical elements of the global hydrological cycle. Spatial distribution of snow depth, an indicator of snow water equivalent, is generally estimated using in-situ measurements or data obtained from weather stations. In-situ measurements are time-consuming and labor-intensive, and even more challenging on complex terrains and heterogeneous landscapes. As such, UAVs could be advantageous for retrieving data over a large area within a shorter time and at a higher spatial resolution and accuracy. Multi-rotor and fixedwing UAV with RGB sensors are commonly used to obtain snow and ice depth. De Michele et al. (2016) used a fixed-wing platform to map snow depth distribution at a centimeter scale over an alpine area in northern Italy. They collected ground elevation data before the snow accumulation and repeated measurements during peak snow accumulation periods. Snow depth and volume were estimated by subtracting the elevation models between those two

measurements. In the Davos region, Switzerland, Bühler et al. (2016) validated UAV-based photogrammetric snow maps using manual measurements to demonstrate their high accuracy (snow depth had a root mean square error (RMSE) of less than 0.07 to $0.15 \mathrm{~m}$ on meadows and rocks and a RMSE of less than $0.30 \mathrm{~m}$ on grass/bushes covered areas). Results obtained from UAV-based photogrammetry were also comparable to a standard method of obtaining snow depth using high-resolution laser scanning (Avanzi et al., 2018). Further, UAV-based LiDARs

This article is protected by copyright. All rights reserved. 
and photogrammetry were used in sub-canopy snow depth measurements. However, the former had better sub-canopy point coverage and error metrics (Harder et al., 2020). Reported RMSEs for snow depth estimates from UAV LiDAR were less than $0.1 \mathrm{~m}$ in open areas and less than $0.17 \mathrm{~m}$ in vegetated areas (Harder et al., 2020). A DJI M-600 hexacopter mounted with a RIEGL miniVUX-1UAV LiDAR sensor was used to study forest canopy interception of snow in the Canadian Rockies (Staines \& Pomeroy, 2019), which further emphasized the importance of UAVs data in snow interception models. More recently, Jacobs et al. (2021) used UAV LiDAR [Eagle XF UAV (UAV America) with VLP-16 LiDAR (Velodyne, Inc.)] to monitor shallow and ephemeral snowpack (less than $20 \mathrm{~cm}$ ) and map snow depth in an open-field and mixedhardwood forest in New Hampshire, USA. Results indicated relatively identical mean snow depths for the in situ and LiDAR measurement in the field, but in situ measurements were nearly two-folds higher than the LiDAR measurement in a forested area. Point cloud density largely determines the performance of such a system (e.g., better scans with high-density point cloud), which ultimately hinges on the flight plan and grid cell variability. Novel photogrammetric approaches have also been proposed to automate image processing and exclude the need to use GCPs while generating digital surface models (Miziński and Niedzielski, 2017). Although UAVs offer several advantages such as efficiency, flexibility, and cost-effectiveness to hydrological surveys, studies can be influenced by solar illumination, wind, and surface heterogeneity (Harder et al., 2020). Indeed, UAVs facilitate improved understanding of snow depth and distribution across heterogeneous landscapes, but more studies are needed.

\subsection{Flood, Drought and Erosion}

Unmanned Aerial Vehicles are useful in delineation of flood-prone areas (Serban et al., 2016), estimation of flood volume and extent (Escobar Villanueva et al., 2019), flood risk modeling 
(Coveney and Roberts, 2017), assessing the impact of flooding (Langhammer and Vacková, 2018), and responding to flood emergencies (Salmoral et al., 2020). Select examples include the use of UAV-based GNSS data in detecting water surfaces on the ground for flood monitoring (Imam et al., 2019) and 2D hydrodynamic modeling using UAV surveys [DJI Matrice 600 UAV with a Zenmuse X5 camera] to detect flash-flood risks (Yalcin, 2019). UAVs-based LiDAR systems are widely tested to monitor land use and land cover interrelationships with flood events, snow interception and distribution, and landslides, erosion, and chute cut-offs. In a recent review, Muhadi et al. (2020) highlighted the use of airborne LiDAR sensors in generating digital surface models (DSMs)/digital terrain models (DTM) to develop flood inundation models and manage flood risks. Lewis et al. (2020) used a Sony A6000 digital single-lens reflex camera to study chute holes in response to land cover change and floods along the East Fork White River, Indiana, US. Results from Lewis and his team highlighted the need to improve and integrate field data with hydrological models. Recently, Kastridis et al. (2020) used UAV surveys to delineate flash flood events of two ephemeral streams in Northern Greece, and to compare and validate results from the Soil Conservation Service-Curve Number (SCS-CN) model and the Hydrologic Modeling System (HEC-RAS) for flood extent and depths. Such integration of UAV surveys and modeling is valuable for estimating natural hazards, formulating mitigation measures, developing conservation strategies, and designing early warning systems under current and projected climatic scenarios (Kastridis et al., 2020). Hashemi-Beni et al. (2018) discussed the key challenges and opportunities of using UAV-based DEM in flood-risk management based on a flood-prone area in North Carolina, US. Briefly, key challenges included wind, camera calibration, point cloud classification to estimate water surface, GCP availability during flood 
events, and processing time as affected by image content, resolution, overlapping, and computer types and processors.

Unmanned Aerial Vehicles equipped with either RGB (Zhang et al., 2019) or thermal infrared sensors (Ludovisi et al., 2017) are used in phenotyping for early detection of drought, evaluating plant responses to drought, and irrigation scheduling. However, due to their lower resolution, hyperspectral sensors are more recently being used in deriving narrow-band vegetative indices for drought and crop water stress monitoring (Dao et al., 2021; Ham et al., 2019). Yet, data processing is complex due to a large number of bands, in particular with spectral derivative technology. As such, efforts are underway to test improved algorithms (e.g., fractional-order derivative algorithms) for enhanced data mining and image classification (Ge et al., 2021).

\subsection{Water Management in Agriculture and Forestry}

UAV platforms could offer new opportunities to the agricultural sector for land classification and land-use change detection (Joshi et al., 2019a; Joshi et al., 2019b; Nguyen et al., 2020; Nguyen et al., 2019), crop scouting (Ehsani and Maja, 2013), and soil moisture management (Gago et al., 2015), among others. In an editorial, Cancela et al. (2019) highlighted three primary uses of UAVs in agricultural water management: (a) characterization of water bodies (Subsection 4.7.1 4.7.2), (b) crop water demand studies (Subsection 4.7.3), and (c) crop water status monitoring (Subsection 4.7.4). A general UAV image processing workflow of RGB and multi-spectral images in agricultural water management is shown in Fig. 4. Below, we briefly discuss UAVs application in the agriculture and forestry sectors separately.

\subsubsection{Characterization of Soil, Water, and Associated Hydrological Processes}

This article is protected by copyright. All rights reserved. 
High-resolution UAVs images provide a means to identify and examine intra-plot near-surface spatial variability and anomalies to inform and support land and water management strategies and priorities. For example, Quiquerez et al. (2014) used a DRELIO unmanned helicopter system consisting of a digital single-lens reflex camera (Nikon D200, 10 MegaPixels) with a $35 \mathrm{~mm}$ focal length lens, an automated piloting system, and a GNSS to characterize soil at $5 \mathrm{~cm}$ resolution in vineyards of Monthelie, France. Soil surface images were classified using Iterative Self Organizing Data Analysis. This technique clusters pixels for soils with similar attributes in homogenous areas using an iterative statistical method. The results showed the potential of high spatial resolution images from the DRELIO for precise mapping of soil and erosional distribution in those vineyards. Similarly, infrared thermography shows the potential for mapping soil surface macropores to better understand soil physical and hydraulic properties in column studies (de Lima et al., 2014).

\subsubsection{Water Quality in Agricultural Ponds and Impoundments}

A few studies have reported using UAVs in agriculture and forestry to monitor water quality in ponds and other impoundments (Koparan et al., 2018; Morgan et al., 2020). Specifically, UAVs with optical and thermal sensors are used to choose sampling locations and in-situ water quality monitoring and mapping. Koparan et al. (2018) developed a multiprobe meter and integrated it with a hexacopter to measure water quality parameters in an agricultural pond in Clemson, South Carolina, US. They compared water quality parameters collected with the hexacopter against a commercial multiprobe meter and reported $2.1 \%, 3.43 \%, 3.76 \%$, and $<1 \%$ differences in dissolved oxygen, EC, pH, and temperature measurements, respectively. They also highlighted the potential to rapidly collect samples and monitor water quality after natural disasters like hurricanes and flooding. Indeed, UAVs data are comparable in terms of accuracy and precision

This article is protected by copyright. All rights reserved. 
to other field sampling and measurement techniques and facilitate hydrological investigations, policies, and management decisions.

\subsubsection{Soil Moisture, Crop Water Demand, and Irrigation}

Advances in UAVs and remote sensing provide a means to gather large-scale information toward myriad hydrologic research objectives more quickly. Soil moisture content is a key constraint that affects biophysical and biogeochemical processes and precipitation, heat transport, carbon uptake, and climate change patterns over the catchment, continental, and global scales (Badía et al., 2017; Kumar et al., 2018). Information on soil moisture plays a pivotal role in tackling existing and foreseeable global food and water scarcity issues through decision support tools and solutions, including flood runoff predictions, water-efficient irrigation, and aquifer storage and recovery (Ge et al., 2019). For example, UAVs have been used in smart water management platforms (SWAMP) for precision irrigation (Kamienski et al., 2019). UAVs combined with augmented reality (AR) technology are used to map soil and guide sampling point selection to represent different management zones (Huuskonen and Oksanen, 2018).

A survey of recent studies indicate the use of UAV-acquired hyper-spatial imagery, including thermal techniques (Paruta et al., 2020), optical data (Lee et al., 2016b), and their synergy (Hassan-Esfahani et al., 2015; Hassan-Esfahani et al., 2017; Wang et al., 2018; Wigmore and Mark, 2018), and GPR systems/microwave (Wu et al., 2019) to estimate soil moisture content. Paruta et al. (2020) used a Phantom 3 quadcopter with a FLIR Tau2 thermal camera and 12.4 MP CMOS sensor RGB camera to capture hyper-spatial images subsequently processed using the apparent thermal inertia method. Similar to other findings in bare soils, their study discerned a strong correlation $\left(R^{2}=0.7\right)$ between soil moisture and apparent thermal inertia for un-shaded

This article is protected by copyright. All rights reserved. 
non-vegetated pixels. Passive microwave sensors exploiting GNSS-reflectometry can be used to obtain soil moisture maps (Alonso-Arroyo et al., 2014; Alonso-Arroyo et al., 2013; Dai et al., 2020; Favenza et al., 2019; Roussel et al., 2016; Thorp et al., 2018) or estimate water surfaces for flood monitoring (Imam et al., 2020). More recently, UAV-acquired GPR data are increasingly used to create high-resolution soil moisture maps. For example, in three agricultural fields in Belgium, a UAV-borne GPR sensor was used to map soil moisture to a depth of $20 \mathrm{~cm}$ (Wu et al., 2019). Overall, soil and moisture mapping using UAVs improve agricultural water use and management from field to regional scales.

\subsubsection{Crop Water Status Monitoring}

Unmanned Aerial Vehicles with MS and hyperspectral cameras are increasingly used in precision agriculture to monitor leaf chlorophyll, leaf water, leaf area index, and plant cover. The amount of light reflected from the plant surface is directly related to the plant types and their chemical and morphological characteristics (e.g., water, chlorophyll, sugar, and carbohydrate) (Chang et al., 2016; Zhang and Kovacs, 2012), and as such, various vegetative indices have been developed (Sishodia et al., 2020). Some common vegetative indices, along with their application, are summarized in Table 9. Briefly, depending on the wavebands, MS sensors are used to calculate Normalized Difference Vegetation Index (NDVI), Normalized Difference Red-Edge Index (NDRE), Leaf Water Content Index (LWCI), Soil-Adjusted Vegetation Index (SAVI), Enhanced Vegetation Index (EVI), and plant water status (Table 9; Allred et al., 2018; Baluja et al., 2012; Poblete et al., 2017). Further, hyperspectral sensors are also used in discriminating and mapping vegetation and predicting leaf area index due to their ability to collect data at several wavebands, mostly at 10 to $20 \mathrm{~nm}$ intervals (Adam et al., 2010). Therefore, vegetative indices offer an important tool to monitor water stress and plant health (Gago et al., 2015; Suárez et al., 
2008; Zhao et al., 2016). Specifically, the crop canopy spectral indices are used to study crop health conditions and to plan and adopt drought management and irrigation strategies (Jay et al., 2019; Thorp et al., 2018). For example, Easterday et al. (2019) used quadcopters to monitor the water stress on Baccharis pilularis (coyote brush) at the Blue Oak Ranch Reserve, California. Plant water status was determined based on NDVI and normalized difference red edge index. Chang et al. (2020) used a UAV system with an integrated thermal camera (a 3DR X8 octocopter system from 3D Robotics, Berkeley, US and a FLIR Vue Pro R 640 radiometric thermal camera from FLIR, Wilsonville, US) to determine cotton canopy temperature and Thermal Stress Index to monitor crop water status. Gomez-Candon et al. (2016) presented a method to obtain thermal and multispectral ortho-imagery and their radiometric correction for monitoring the water stress of apple trees. The approach incurred lower time for image processing and calibration, improved cost efficiency, and further aided in plant phenotyping programs for water limitation. UAVs also help monitor plant water use efficiency, which further helps identify and select plant varieties for breeding and crop improvement. However, there are multiple challenges associated with estimating water status and stress, such as effects of solar motion on canopy NDVI and characteristics and effects of the bidirectional reflectance distribution function, which deserve considerable attention. Zhao et al. (2017) reported a co-relation coefficient of 0.33 between stem water potential and canopy NDVI; emphasizing the effects of the bidirectional reflectance distribution function. Indeed, pixels with lower NDVI can denote restricted or absence of direct illumination from the sun. Wider field-of-view and solar motion is related to the angular effects or the bidirectional reflectance distribution function. Such geometry of illumination is a common source of error in remote sensing. Wide views are generally associated with lens distortion and

This article is protected by copyright. All rights reserved. 
thus "radial variation in viewing angle", whereas solar motion to "non-static illumination" in photogrammetric applications (Starks et al., 2016).

\section{Subsurface Hydrology and Water Management}

Unmanned aerial systems can be of high value for site reconnaissance to plan hydrological monitoring and deploy sensors for studies relating to below-ground drainage networks and below the water surface. UAVs with thermal infrared imagery characterize groundwater systems and monitor subsurface processes, hydro-chemical elements, and complex hydrological interactions at various scales. Such studies include below-ground tile drainage (Section 6.1), subsurface hydrogeochemistry (Section 6.2), and groundwater discharge (Section 6.3).

\subsection{Subsurface Tile Drainage}

The use of tile drainage is extensive in agricultural regions. Monitoring and mapping belowground drainage lines reduce repair costs, improve the efficacy of tile networks, and help to manage water and nutrients in agricultural and natural systems (Barnsdale, 2014). Tilahun (2019) used a FLIR Vue Pro R sensor, DJI FC 6510 Zenmuse X4S RGB, and the DJI FC330 Phantom 4 Quadcopter camera mounted to map subsurface tile drainage in an agricultural field. The results demonstrated the efficacy of using thermal sensors to improve tile drainage mapping after rainfall events. In similar experiments, UAV surveys with VIS, NIR, and TIR sensors were used to map subsurface drainage systems in a dry agricultural field in central Ohio (Allred et al., 2018). While VIS and NIR sensors failed to detect drainage pipes, thermal infrared imagery mapped $66 \%$ of drainage pipes in their study. In another study consisting of 29 sites from four

Midwest US states, visible, MS, and TIR sensors detected drainage lines at 48, 59, and 69\% of

This article is protected by copyright. All rights reserved. 
the sites, respectively. Although TIR sensor detected drainage lines at more sites, visible or MS sensors, and a combination of MS and TIR sensors were more effective in a few cases (Allred et al., 2020). Thus, more studies are warranted to identify and deploy appropriate sensors for different soil types and dryness/wetness conditions (Allred et al., 2018).

\subsection{Subsurface Hydrogeochemistry}

UAV-based hyperspectral sensing of water reflectance and pigment distribution and concentration has been extensively tested to monitor below water surface hydrogeochemistry in deep reservoirs and other aquatic systems. Hyperspectral sensors have high absorption at nearinfrared wavelengths, which show promising results in monitoring and mapping harmful algal blooms. Kwon et al. (2020) used UAV-based hyperspectral remote sensing, such as subsurface reflectance, to study cyanobacterial pigment in a deep reservoir. They used a Nano-Hyperspec® hyperspectral imager mounted on a MATRICE M600 Pro hexacopter to measure reflectance and a band-ratio algorithm to estimate pigment concentrations. The correlation $\left(\mathrm{R}^{2}\right)$ between in-situ reflectance and drone reflectance was 0.85 . Surface and cumulative pigment estimates using the drone-reflectance band ratio showed a weak correlation. However, vertical cumulative concentration improved the performance of bio-optical algorithms. Hutchings et al. (2019) used a Phantom 3 Standard drone to study subsurface geochemistry and redox conditions in East Anglian salt marshes with two types of sediment chemistry, sulfide-rich and iron-rich pond sediments. Undeniably, UAVs appear to be a useful tool to better understand subsurface geochemistry and thus nutrient and carbon cycling in wetlands and aquatic systems.

This article is protected by copyright. All rights reserved. 


\subsection{Groundwater Discharge}

Groundwater discharge transports water and nutrients, and mapping them is crucial. Recently, thermal infrared techniques have been extensively tested for point-in-time monitoring of surface water-groundwater mixing sites and mapping submarine discharge in coastal areas at a temperature resolution of approximately $0.1^{\circ} \mathrm{C}$. Lee et al. (2016a, b) used UAVs with highresolution aerial thermal infrared sensors to map the nutrient discharge of submarine groundwater adjacent to Jeju Island, Korea. They observed low-temperature signatures of submarine groundwater discharge along the coast, possibly affecting the sea surface temperature (Lee et al., 2016a). Thermal imagery is also used to identify sub-aerial springs and map turbidity plumes caused by groundwater discharge (Kolokoussis et al., 2011). Abolt et al. (2018) tested a microbolometer mounted in UAV to derive high-quality temperature maps at a discharge site in Texas, US. Although temperature differences could identify recharge and discharge areas, in some cases, the technique failed in others due to sensitivity to wind, vegetation shading, and changing river levels effects (Coluccio and Morgan, 2019). Also, UAVs could improve water level estimates to increase the accuracy and reliability of estimates for surface watergroundwater interactions for hydrological models (Bandini et al., 2017). Indeed, UAV surveys show promise as a tool for mapping groundwater discharge, but studies are few, warranting further research.

\section{Land-Atmosphere Interactions}

The very high spatial resolution hyperspectral, MS, or thermal IR remote sensing data provide great potential to characterize vegetation traits and soil properties to quantify ecosystem fluxes

This article is protected by copyright. All rights reserved. 
between the land surface and the atmosphere (Vivoni et al., 2014). UAVs have been utilized in eddy covariance land surface flux sites to study land-atmosphere interactions to understand ecohydrological processes (Anderson and Gaston, 2013; Hardin and Jensen, 2011; Wang et al., 2019a). Fig. 3 depicts a UAV imaging payload consisting of a RGB camera, a thermal infrared camera, and a multispectral camera used in monitoring land surface energy, water, and $\mathrm{CO}_{2}$ fluxes. Hoffmann et al. (2016) demonstrated that high-resolution UAV thermal IR imagery could be combined with two-source energy balance models to quantify evapotranspiration. The Grape Remote Sensing Atmospheric Profile and Evapotranspiration eXperiment (GRAPEX) project investigated the benefits of incorporating high-resolution UAV thermal IR and optical imagery into TSEB models to assess the spatial variability of evapotranspiration in vineyards (Kustas et al., 2018, 2019). Such high-resolution UAV imagery could facilitate evapotranspiration partitioning between vine and interrow to understand the effects of canopy architecture (Nieto et al., 2019) and shadows (Aboutalebi et al., 2019) on surface-atmosphere energy exchanges. In an oil palm plantation, an MK EASY Okto V3 octocopter equipped with a FLIR Tau 2 thermal camera and an Omnivision CMOS-Sensor was used to compare latent heat flux and evapotranspiration between measurements from UAV imagery and eddy covariance methods (Ellsäßer et al., 2020). A good correlation between the DATTUTDUT model and eddy covariance existed for latent heat flux $\left(\mathrm{R}^{2}=0.85\right)$ across all daytime and weather conditions, and the results underscored the utility of UAV-based thermography for integrating miniaturized radiation sensors to estimate radiation budgets. Wang et al. (2019a) developed an operational framework to synthesize the RGB, MS, and thermal IR data from a hexacopter to monitor land surface energy, water, and $\mathrm{CO}_{2}$ fluxes in a bioenergy plantation eddy flux site in Denmark with a very high spatial resolution (less than $1 \mathrm{~m}$ ). This study demonstrated that UAV-acquired imagery

This article is protected by copyright. All rights reserved. 
could capture the spatial heterogeneity of ecosystem carbon assimilation, water use, energy balance, and water use efficiency, which could bring significant benefits for water resource management in precision agriculture. Furthermore, Wang et al. (2020) developed a dynamic soilvegetation-atmosphere transfer model to temporally interpolate the UAV-based snapshots of land surface fluxes into continuous estimates. Thomas et al. (2012) designed and tested a UAV system to collect turbulent water vapor flux data and further improve understanding of cloud dynamics and aerosol interactions. These studies demonstrated that UAV-derived data could better epitomize spatial and temporal variabilities in fluxes than eddy tower systems and satellite-based remote sensing. Indeed, compared to other remote sensing platforms, UAVs with flexible sensor payloads provide unique high-resolution remote sensing data to promote studies of land surface-atmosphere interactions to facilitate water management decisions.

\section{Other Applications}

This section discusses the application of a range of UAV mounted sensors, including fluid lensing for ecosystem monitoring (Subsection 8.1) and hydrological modeling (Subsection 8.2).

\subsection{Ecosystem Monitoring}

UAVs-based SfM and multi-view stereo reconstructions are widely used to map and model vegetative and aquatic ecosystems at centimeter resolution (Dietrich, 2017; Mancini et al., 2013; Navarro et al., 2020). For example, UAVs were used to estimate species composition in temperate grasslands ( $\mathrm{Lu}$ and $\mathrm{He}, 2018$ ), above-ground biomass in mangrove ecosystems (Navarro et al., 2020), and to monitor seasonal change in NDVI, biomass, and gross primary productivity (GPP) in the Arctic ecosystems (Siewert and Olofsson, 2020). In the latter example, the authors also highlighted the potential of UAVs to resolve compositional and configurational

This article is protected by copyright. All rights reserved. 
heterogeneity and validate satellite-based data on ecosystem properties. Arroyo-Mora et al. (2019) used an UAV HS system consisting of the Matrice 600 Pro hexacopter (DJI, Shenzhen, China), the micro Compact Airborne Spectrographic Imager ( $\mu$ CASI; 288 spectral bands from 401-996 nm, ITRES Research Ltd., Calgary, AB, Canada), and an IMU/GNSS unit for monitoring three distinct ecosystems (peatland, herbaceous field, and oak forest) that were a part of the Canadian Airborne Biodiversity Observatory Project.

Airborne fluid lensing on UAVs is another passive remote sensing technique, which uses watertransmitting wavelengths to capture images of underwater objects at a centimeter scale (Chirayath and Earle, 2016). Fluid lensing appears as a promising tool for assessing the conservation status of reefs and other aquatic ecosystems. However, surface-wave distortion and optical properties of water may alter/influence signal-to-noise ratio and spatial resolution (Chirayath and Earle, 2016). Also, UAVs can be used to understand how different ecosystems respond and adapt to climatic change and variability (Arroyo-Mora et al., 2019). Indeed, UAVs provide multiple data products and rapid and flexible methods to study ecosystems' properties and functions and guide management and conservation priorities. However, such studies are few, and further research is required to fully understand the potential for UAVs in this area of investigation.

\subsection{Modeling}

Unmanned Aerial Vehicles and low-altitude photogrammetry have been consistently applied in hydrology to develop topographical models (Lowe et al., 2019; Resop et al., 2019) and optimize natural hazards modeling (Backes et al., 2019). UAVs improve DEM and vegetation

This article is protected by copyright. All rights reserved. 
classification with reduced survey time and cost for hydrological measurements and modeling, including water stress, floods, and landslides. UAV SfM has been shown to produce DEMs competitive with expensive LiDAR scans in terrain mapping and hydrodynamic modeling (Javernick et al., 2014). In riparian zones, the accuracy of stream temperature models parameterized using UAV-based SfM tree height data was compared with LiDAR tree height data (Dugdale et al., 2019). SfM model showed a higher degree of accuracy, while the average RMSE was identical to the LiDAR approach. Such methods are likely prone to the effects of dense forest canopies on acquiring point clouds that accurately measure ground elevation, which should be investigated in future research.

High-resolution DTMs derived from UAV imagery have been used in flood prediction models (e.g., LISFLOOD-FP) to simulate water flows and depths (Backes et al., 2019) and calibrate and validate satellite-based products (Vivoni et al., 2014). One such example is the use of drone imagery in training classification algorithms and validation of satellite imagery in estuarine wetlands in the Rachel Carson Reserve in North Carolina, US (Gray et al., 2018). Further, hyperspatial imagery can be used to train fuzzy classification models in fluvial studies (Carbonneau et al., 2020). UAV-derived DSMs are valuable in peri-urban areas to detect small-scale hydrological features like thin walls affecting runoff and flooding (Annis et al., 2020). UAVderived DEMs have shown better performance than other DEMs, such as TINITALY DEM, a nation-scale high-resolution DEM in Italy, for flood extension and flow depth monitoring (Annis et al., 2020).

UAV-based LiDAR has been tested for modeling stream topography and vegetation. For example, a Vapor 35 drone (Pulse Aerospace Inc., Lawrence, KS) with an integrated YellowScan Surveyor Core LiDAR (Montferrier-sur-Lez, France)] was compared with airplane- 
based laser scanning [Leica ALS-50 LiDAR and Optech Galaxy Airborne Laser Terrain Mapper]

for modeling stream topography and vegetation in Virginia, US (Resop et al., 2019). UAV-based

LiDAR imagery produced a high-resolution terrain model and canopy height model to represent

channel profile and floodplain vegetation of less than $1 \mathrm{~m}$ in height compared with airplane based scanning. UAS-photography based bathymetric modeling has been used to develop seamless DEM of river bend to study fluvial processes and riverbed evolution (Flener et al., 2013; Ozcan and Akay, 2018). Importantly, the accuracy of photogrammetry point clouds depend on the number of images used in the model development and their geometric quality, among other factors such as image lens distortion and sharpness (Flener et al., 2013). Overall, UAV photogrammetry and automated sensors networks show promise in developing comprehensive hydrodynamic flood models. However, UAV-based photogrammetry displays limited use under turbulent flow and irregular stream bottom with variable depth for stream bathymetry reconstruction (Langhammer et al., 2017).

\section{Challenges}

UAVs applications in hydrology present many new opportunities for hydrologic research and a platform for new techniques of data acquisition. However, below we highlight some challenges of using UAVs in hydrology and water resource management:

- Studies indicate several challenges associated with using small UAVs in environmental remote sensing. Small UAVs are constrained by their weight, adverse weather (wind, rain, turbulence), and availability of accurate, precise, and affordable sensors. Further,

This article is protected by copyright. All rights reserved. 
geo-referencing and processing a large volume of images present computation workloads that can overwhelm even fast computers (Hardin and Jensen, 2011).

- Reconstructing homogenous and moving objects such as snow and water surfaces using SfM algorithms is somewhat challenging (Jeziorska, 2019). There are considerable uncertainties linked to image quality (lens distortion, image focus, image resolution, and perspective) in determining water level (Ridolfi and Manciola, 2018). The importance of steady and detectable points on the water surface to estimate water surface elevation has also been established in other studies (Bandini et al., 2020). However, identifying and obtaining ground control points for orthorectification and acquiring sharp images with good focus, resolution, and perspective remain challenging, especially in adverse conditions, warranting further exploration and improvements (Ridolfi and Manciola, 2018).

- Challenges remain in developing or improving algorithms for processing low altitude hyperspectral imagery (Arroyo-Mora et al., 2019).

- While vegetation indices derived from UAVs imagery offer important plant physiological information, measurement of vegetation indices is affected by solar angle, climate, topography, and radiometric calibrations, among other factors (Easterday et al., 2019).

- UAVs are constrained by limited flight durations (Cancela et al., 2019; Koparan et al., 2018). Larger fixed-winged UAVs are challenging to deploy and often incur higher initial costs than small quadcopters (Klemas, 2015). Likewise, flights are affected by environmental conditions (lighting, wind, air humidity) and battery life, among other factors. For example, in-flight changes in solar irradiance significantly affect the quality

This article is protected by copyright. All rights reserved. 
of UAVs imagery (Wang et al., 2019b). Greater flight altitude reduces the spatial resolution of images and water vapor in the air may attenuate the signals transmitted from imaging surfaces (Still et al., 2019).

- There are safety issues associated with UAVs usage primarily due to spatial coverage and interference with civilian aircraft (Hardin and Jensen, 2011). Flights beyond visible lineof-sight could potentially increase cost-benefit ratios (Dyer et al., 2020). Similarly, in the US, the maximum flight altitude is $120 \mathrm{~m}$ above ground level, and UAVs are not permitted to fly at night. Changes to these rules could impair or enhance the efficiency of UAVs data acquisition techniques. Safety requirements such as when to fly (day vs. night), where to fly, and UAVs characteristics (weight, speed, height from ground) vary with meteorological conditions, data type and complexity. Yasin et al. (2020) highlighted and reviewed different collision avoidance methods and reported reactive planning, deliberate planning, hybrid approaches, and four different algorithms: geometric, forcefield, optimization-based, and sense and avoid methods. Indeed, the growing breadth of literature suggests an increasing need to develop better collision avoidance systems and assure the public and regulators that UAVs are safe to operate in the environment.

- Regulations for piloting and operating UAVs continue to evolve and vary significantly from nation to nation and even in different areas within the same country (Klemas, 2015). Operators must receive proper training and UAVs must be registered appropriately according to local regulations, which may include provisions for reporting accidents, collision avoidance system requirements, etc. (Cracknell, 2017).

This article is protected by copyright. All rights reserved. 
- Aviation policies and regulations are key constraints on the further development of research and commercial applications of UAVs technology. They will continue to govern future innovations and opportunities for UAV platforms (Chávez et al., 2020).

\section{Opportunities and Prospects}

The use of UAVs, different platforms, sensors, and payloads offer tremendous opportunities to researchers, scientists, managers, and policymakers for spatial and temporal monitoring, measurement, mapping, and management of water resources. The different opportunities and prospects of using UAVs are highlighted below:

- UAVs can reach adverse, risk-prone, and human inaccessible areas. Indeed, UAVs enable hydrological monitoring in previously ungauged locations (Tauro et al., 2016b), and data could be coupled with in-situ measurements to improve decision-making and planning. For example, Vivoni et al. (2014) highlighted opportunities for integrating UAVs data with long-term data from the Long-term Ecological Research Network (LTER) or the National Ecological Observing Network (NEON). Field-based plant water content measurements integrated to UAV-based measurements of vegetation indices (Easterday et al., 2019) allow for an improved understanding of plant water stress and demand to identify and prioritize management options under climatic extremes. Similarly, surface water level information could be used to develop stage-damage curves and evaluate insurance policies against floods (Bandini et al., 2017). Overall, UAVs provide multiple opportunities to understand spatial and temporal heterogeneities in blue water and green water under variable climate and land-use systems to foster sustainable land and water use and management and improve infrastructure development.

This article is protected by copyright. All rights reserved. 
- Small UAVs pose opportunities to obtain high-quality images at a relatively lower price. However, more research is warranted to improve sensors, automate flights, and increase flight duration by developing better vertical take-off and landing (VTOL) platforms (Becker et al., 2019). For example, while monitoring water quality in an agricultural pond, Koparan et al. (2018) used 13 waypoints for their hexacopter. The three flight missions had a flight length of $256 \mathrm{~m}, 396 \mathrm{~m}$, and $166 \mathrm{~m}$ for the first, second, and third missions, respectively. Powerful batteries with longer endurance could have reduced the mission to a single flight. Likewise, improvements in radar technologies could potentially improve hydrological monitoring and data acquisitions.

- Image mosaicking and field of view reconstruction approaches show promise for flow monitoring over a large area (Perks 2020; Tauro et al., 2016b). Further, UAVs could be combined with radar altimetry to better predict water surface elevation (Bandini et al., 2020), and with LiDAR, sonar, or optically-based bathymetric measurements to determine flow rates

- UAVs could be modified with greater payload capacity, which allows for the rapid collection of a large volume of water samples (Lally et al., 2019). However, it will increase initial costs, time to set-up/deploy UAVs, and licensing requirements. More studies are needed to improve the reliability and accuracy of sampling. Furthermore, a detailed cost-benefit analysis would enhance the decision-making process in water monitoring programs.

- High-resolution spatial, temporal, and continuous UAV-based physical, chemical, or biological data could be used to parameterize, calibrate and validate satellite-based products, and hydrological, ecohydrological, and geophysical models (Vivoni et al., 
2014). This could, however, require multiple flights using the same UAVs or UAVs equipped with similar sensors over an area at a time. Multiple flights along with tilted cameras have also been shown to improve the vertical accuracy of SfM products such as DSMs (Manfreda et al., 2019). Also, there are many opportunities to coordinate data collection procedures, develop better data processing systems, and integrate data from multiple sources.

- Artificial intelligence, machine learning techniques, and algorithms should be explored and identified to correct noise in images/photos, reduce positional errors (Arroyo-Mora et al., 2019), and understand flow velocimetry (Tauro et al., 2016b).

- The high-resolution nature of the imagery and other data acquired using UAVs yields large datasets that require considerable space to store and archive. Both the reproducibility of scientific investigations and the likelihood that future changes in the landscape will make data collected earlier in time of interest to future researchers strongly suggest a need for central data repositories and standards for archiving and storing UAV-derived data.

- Challenges associated with UAVs have raised global urgency and needs among different disciplines and agencies to collaborate and to technology transfer, and further unlocked opportunities to involve the general public in citizen science.

\section{Conclusions}

In Summary, we reviewed the use of UAVs in hydrology and water management and highlighted major challenges, opportunities, and prospects of utilizing UAVs. UAVs present effective tools

This article is protected by copyright. All rights reserved. 
for monitoring natural resources, such as soil, water, biomes, and hydrological processes at much finer space and in real-time. UAV-borne sensors data could be used to parameterize and validate satellite-based products, and hydrological and geophysical models. Also, UAVs show great promise under climatic change and variability. However, the technology is still evolving, and challenges exist, which require global collaboration, training support, technology transfer, and data sharing and archiving.

\section{Declaration of Competing Interest}

The authors declare that they have no known competing financial interests or personal relationships that could have appeared to influence the work reported in this paper.

\section{Disclaimer}

The authors are responsible for the views expressed in this paper and do not necessarily represent or reflect the views and policies of the Oklahoma Department of Mines and universities.

\section{Data Availability}

No new data was used in the paper

This article is protected by copyright. All rights reserved. 


\section{References}

Abolt C., Caldwell T., Wolaver B., Pai H. (2018) Unmanned aerial vehicle-based monitoring of groundwater inputs to surface waters using an economical thermal infrared camera. Optical Engineering 57:053113.

Aboutalebi M., Torres-Rua A.F., Kustas W.P., Nieto H., Coopsman C., McKee M. (2019) Assessment of different methods for shadow detection in high-resolution optical imagery and evaluation of shadow impact on calculation of NDVI and evapotranspiration. Irrigation Science 37(3):407429. https://doi.org/10.1007/s00271-018-0613-9

Acevo-Herrera R., Aguasca A., Bosch-Lluis X., Camps A. (2009) On the use of compact L-band Dicke radiometer (ARIEL) and UAV for soil moisture and salinity map retrieval: 2008/2009 field experiments, 2009 IEEE International Geoscience and Remote Sensing Symposium. pp. IV-729IV-732.

Acevo-Herrera R., Aguasca A., Bosch-Lluis X., Camps A., Martínez-Fernández J., Sánchez-Martín N., Pérez-Gutiérrez C. (2010) Design and First Results of an UAV-Borne L-Band Radiometer for Multiple Monitoring Purposes. Remote Sensing 2:1662-1679.

Acharya B.S., Kharel G. (2020) Acid Mine Drainage from Coal Mining in the United States-An Overview. Journal of Hydrology:125061.

Adam E., Mutanga O., Rugege D. (2010) Multispectral and hyperspectral remote sensing for identification and mapping of wetland vegetation: a review. Wetlands Ecology and Management 18:281-296.

Ahongshangbam J., Khokthong W., Ellsäßer F., Hendrayanto H., Hölscher D., Röll A. (2019) Drone based photogrammetry - derived crown metrics for predicting tree and oil palm water use. Ecohydrology 12(6): e2115.

Alimenti F., Bonafoni S., Gallo E., Palazzi V., Gatti R.V., Mezzanotte P., Roselli L., Zito D., Barbetta S., Corradini C., Termini D., Moramarco T. (2020) Noncontact Measurement of River Surface Velocity and Discharge Estimation With a Low-Cost Doppler Radar Sensor. IEEE Transactions on Geoscience and Remote Sensing 58:5195-5207. DOI: 10.1109/TGRS.2020.2974185.

Allred B., Eash N., Freeland R., Martinez L., Wishart D. (2018) Effective and efficient agricultural drainage pipe mapping with UAS thermal infrared imagery: A case study. Agricultural Water Management 197:132-137.

Allred B., Martinez L., Fessehazion M.K., Rouse G., Williamson T.N., Wishart D., Koganti T., Freeland R., Eash N., Batschelet A., Featheringill R. (2020) Overall results and key findings on the use of UAV visible-color, multispectral, and thermal infrared imagery to map agricultural drainage pipes. Agricultural Water Management 232:106036.

Alonso-Arroyo A., Camps A., Monerris A., Rüdiger C., Walker J.P., Forte G., Pascual D., Park H., Onrubia R. (2014) The light airborne reflectometer for GNSS-R observations (LARGO) instrument: Initial results from airborne and Rover field campaigns, 2014 IEEE Geoscience and Remote Sensing Symposium. pp. 4054-4057.

Alonso-Arroyo A., Forte G., Camps A., Park H., Pascual D., Onrubia R., Jove-Casulleras R. (2013) Soil moisture mapping using forward scattered GPS L1 signals, 2013 IEEE International Geoscience and Remote Sensing Symposium-IGARSS, IEEE. pp. 354-357.

Alvarez L.V., Moreno H.A., Segales A.R., Pham T.G., Pillar-Little E.A., Chilson P.B. (2018) Merging Unmanned Aerial Systems (UAS) Imagery and Echo Soundings with an Adaptive Sampling Technique for Bathymetric Surveys. Remote Sensing 10:1362.

Alzu'bi H., Mansour I., Rawashdeh O. (2018) Loon copter: Implementation of a hybrid unmanned aquatic-aerial quadcopter with active buoyancy control. Journal of field Robotics 35:764-778.

Amigo J.M., Santos C. (2020) Preprocessing of hyperspectral and multispectral images, Data Handling in Science and Technology, Elsevier. pp. 37-53.

This article is protected by copyright. All rights reserved. 
Anderson K., Hancock S., Disney M., Gaston K.J. (2016) Is waveform worth it? A comparison of LiDAR approaches for vegetation and landscape characterization. Remote Sensing Ecology and Conservation 2:5-15.

Anderson K., Gaston K.J. (2013) Lightweight unmanned aerial vehicles will revolutionize spatial ecology. Frontiers in Ecology and the Environment 11:138-146.

Annis A., Nardi F., Petroselli A., Apollonio C., Arcangeletti E., Tauro F., Belli C., Bianconi R., Grimaldi S. (2020) UAV-DEMs for Small-Scale Flood Hazard Mapping. Water 12(6):1717.

Arroyo-Mora J.P., Kalacska M., Inamdar D., Soffer R., Lucanus O., Gorman J., Naprstek T., Schaaf E.S., Ifimov G., Elmer K., Leblanc G. (2019) Implementation of a UAV-Hyperspectral Pushbroom Imager for Ecological Monitoring. Drones 3:12.

Australian Government, Bureau of Meterology. (2020) National Industry Guidelines for hydrometric monitoring Part 11: Application of surface velocity methods for velocity and open channel discharge measurements. Water Monitoring Standarization Technical Committee. NI GL 100.112020. Available from:

http://www.bom.gov.au/water/standards/DRAFT_Surface_Velocity_Methods_National_Industry _Guideline_Ver_1.51.pdf [Accessed 9 February 2021]

Avanzi F., Bianchi A., Cina A., De Michele C., Maschio P., Pagliari D., Passoni D., Pinto L., Piras M., Rossi L. (2018) Centimetric accuracy in snow depth using unmanned aerial system photogrammetry and a multistation. Remote Sensing 10:765.

Backes D., Schumann G., Teferele F., Boehm J. (2019) Towards a high-resolution drone-based 3D mapping dataset to optimise flood hazard modelling. The International Archives of the Photogrammetry, Remote Sensing and Spatial Information Sciences 42:181-187.

Badía D., López-García S., Martí C., Ortíz-Perpiñá O., Girona-García A., Casanova-Gascón J. (2017) Burn effects on soil properties associated to heat transfer under contrasting moisture content. Science of the Total Environment 601-602:1119-1128. DOI: https://doi.org/10.1016/j.scitotenv.2017.05.254.

Bagheri O., Ghodsian M., Saadatseresht M. (2015) Reach scale application of UAV+SfM method in shallow rivers hyperspatial bathymetry, Copernicus GmbH, Gottingen. pp. 77-81.

Balsi M., Moroni M., Chiarabini V., Tanda G. (2021) High-Resolution Aerial Detection of Marine Plastic Litter by Hyperspectral Sensing. Remote Sensing 13(8):1557.

Baluja J., Diago M.P., Balda P., Zorer R., Meggio F., Morales F., Tardaguila J. (2012) Assessment of vineyard water status variability by thermal and multispectral imagery using an unmanned aerial vehicle (UAV). Irrigation Science 30:511-522.

Bandini F., Butts M., Jacobsen T.V., Bauer - Gottwein P. (2017) Water level observations from unmanned aerial vehicles for improving estimates of surface water-groundwater interaction. Hydrological Processes 31:4371-4383.

Bandini F., Lopez-Tamayo A., Merediz-Alonso G., Olesen D., Jakobsen J., Wang S., Garcia M., BauerGottwein P. (2018a) Unmanned aerial vehicle observations of water surface elevation and bathymetry in the cenotes and lagoons of the Yucatan Peninsula, Mexico. Hydrogeology Journal 26:2213-2228.

Bandini F., Olesen D., Jakobsen J., Kittel C.M.M., Wang S., Garcia M., Bauer-Gottwein P. (2018b) Technical note: Bathymetry observations of inland water bodies using a tethered single-beam sonar controlled by an unmanned aerial vehicle. Hydrology and Earth System Sciences 22:41654181. DOI: $10.5194 /$ hess-22-4165-2018.

Bandini F., Sunding T.P., Linde J., Smith O., Jensen I.K., Köppl C.J., Butts M., Bauer-Gottwein P. (2020) Unmanned Aerial System (UAS) observations of water surface elevation in a small stream: Comparison of radar altimetry, LIDAR and photogrammetry techniques. Remote Sensing of Environment 237:111487.

This article is protected by copyright. All rights reserved. 
Banerjee B.P., Raval S., Maslin T.J., Timms W. (2020) Development of a UAV-mounted system for remotely collecting mine water samples. International Journal of Mining, Reclamation and Environment 34:385-396.

Barnsdale K. (2014) Delineating tile drain networks using infrared imagery from drones-Final report.

Becker R.H., Sayers M., Dehm D., Shuchman R., Quintero K., Bosse K., Sawtell R. (2019) Unmanned aerial system based spectroradiometer for monitoring harmful algal blooms: A new paradigm in water quality monitoring. Journal of Great Lakes Research 45:444-453.

Becker R.H., Sultan M.I., Boyer G.L., Twiss M.R., Konopko E. (2009) Mapping cyanobacterial blooms in the Great Lakes using MODIS. Journal of Great Lakes Research 35:447-453.

Beene D., Zhang S., Paulus G. (2019) Workflow for hydrologic modelling with sUAS-acquired aerial imagery. Geocarto International:1-19.

Bergsma E.W., Almar R., de Almeida L.P.M., Sall M. (2019) On the operational use of UAVs for videoderived bathymetry. Coastal Engineering 152:103527.

Bhandari M., Ibrahim A.M., Xue Q., Jung J., Chang A., Rudd J.C., Maeda M., Rajan N., Neely H., Landivar J. (2020) Assessing winter wheat foliage disease severity using aerial imagery acquired from small Unmanned Aerial Vehicle (UAV). Computers and Electronics in Agriculture 176:105665.

Bhardwaj A., Sam L., Martín-Torres F.J., Kumar R. (2016) UAVs as remote sensing platform in glaciology: Present applications and future prospects. Remote Sensing of Environment 175:196204.

Bhardwaj V., Kaur N., Vashisht S., Jain S. (2020) SecRIP: Secure and reliable intercluster routing protocol for efficient data transmission in flying ad hoc networks. Transactions on Emerging Telecommunications Technologies:e4068.

Bjerklie D.M., Fulton J.W., Dingman S.L., Canova M.G., Minear J.T., Moramarco T. (2020) Fundamental Hydraulics of Cross Sections in Natural Rivers: Preliminary Analysis of a Large Data Set of Acoustic Doppler Flow Measurements. Water Resources Research 56:e2019WR025986.

Blöschl G., Bierkens M.F., Chambel A., Cudennec C., Destouni G., Fiori A., Kirchner J.W., McDonnell J.J., Savenije H.H., Sivapalan M. (2019) Twenty-three unsolved problems in hydrology (UPH)-a community perspective. Hydrological Sciences Journal 64:1141-1158.

Boon M., Drijfhout A., Tesfamichael S. (2017) Comparison of a fixed-wing and multi-rotor uav for environmental mapping applications: a case study. The International Archives of Photogrammetry, Remote Sensing and Spatial Information Sciences 42:47.

Brodie K.L., Bruder B.L., Slocum R.K., Spore N.J. (2019) Simultaneous Mapping of Coastal Topography and Bathymetry From a Lightweight Multicamera UAS. IEEE Transactions on Geoscience and Remote Sensing 57:6844-6864. DOI: 10.1109/TGRS.2019.2909026.

Bühler Y., Adams M.S., Bösch R., Stoffel A. (2016) Mapping snow depth in alpine terrain with unmanned aerial systems (UASs): potential and limitations. The Cryosphere 10:1075-1088. DOI: 10.5194/tc-10-1075-2016.

Cancela J.J., González X.P., Vilanova M., Mirás-Avalos J.M. (2019) Water management using drones and satellites in agriculture, Multidisciplinary Digital Publishing Institute.

Capolupo A., Pindozzi S., Okello C., Boccia L. (2014) Indirect field technology for detecting areas object of illegal spills harmful to human health: application of drones, photogrammetry and hydrological models. Geospatial Health:S699-S707.

Capolupo A., Pindozzi S., Okello C., Fiorentino N., Boccia L. (2015) Photogrammetry for environmental monitoring: The use of drones and hydrological models for detection of soil contaminated by copper. Science of the Total Environment 514: 298-306.

Carbonneau P., Belletti B., Micotti M., Lastoria B., Casaioli M., Mariani S., Marchetti G., Bizzi S. (2020) UAV - based training for fully fuzzy classification of Sentinel - 2 fluvial scenes. Earth Surface Processes and Landforms.

This article is protected by copyright. All rights reserved. 
Casella E., Collin A., Harris D., Ferse S., Bejarano S., Parravicini V., Hench J.L., Rovere A. (2017) Mapping coral reefs using consumer-grade drones and structure from motion photogrammetry techniques. Coral Reefs 36:269-275.

Castendyk D.N., Straight B.J., Voorhis J.C., Somogyi M.K., Jepson W.E., Kucera B.L. (2019) Using aerial drones to select sample depths in pit lakes, in: A. B. Fourie and M. Tibbett (Eds.), Proceedings of the 13th International Conference on Mine Closure, Australian Centre for Geomechanics, Perth. pp. 1113-1126.

Chabot D. (2018) Trends in drone research and applications as the Journal of Unmanned Vehicle Systems turns five. Journal of Unmanned Vehicle Systems 6:vi-xv.

Champagne C., Rowlandson T., Berg A., Burns T., L'Heureux J., Tetlock E., Adams J.R., McNairn H., Toth B., Itenfisu D. (2016) Satellite surface soil moisture from SMOS and Aquarius: Assessment for applications in agricultural landscapes. International Journal of Applied Earth Observation and Geoinformation 45:143-154. DOI: https://doi.org/10.1016/j.jag.2015.09.004.

Chang A., Jung J., Maeda M.M., Landivar J.A., Carvalho H.D., Yoem J. (2020) Measurement of Cotton Canopy Temperature Using Radiometric Thermal Sensor Mounted on the Unmanned Aerial Vehicle (UAV). Journal of Sensors 2020.

Chang L., Peng-Sen S., Shi-Rong L. (2016) A review of plant spectral reflectance response to water physiological changes. Chinese Journal of Plant Ecology 40:80-91.

Chávez J.L., Torres-Rua A., Boldt W.E., Zhang H., Robertson C., Marek G., Wang D., Heeren D., Taghvaeian S., Neale C.M. (2020) A Decade of Unmanned Aerial Systems in Irrigated Agriculture in the Western US. Applied Engineering in Agriculture:0.

Chirayath V., Earle S.A. (2016) Drones that see through waves-preliminary results from airborne fluid lensing for centimetre - scale aquatic conservation. Aquatic Conservation: Marine and Freshwater Ecosystems 26:237-250.

Chiu C.L. (1991) Application of Entropy Concept in Open\&\#x2010;Channel Flow Study. Journal of Hydraulic Engineering 117:615-628. DOI: doi:10.1061/(ASCE)0733-9429(1991)117:5(615).

Cledat E., Jospin L.V., Cucci D.A., Skaloud J. (2020) Mapping quality prediction for RTK/PPK-equipped micro-drones operating in complex natural environment. ISPRS Journal of Photogrammetry and Remote Sensing 167:24-38. DOI: https://doi.org/10.1016/j.isprsjprs.2020.05.015.

Colomina I., Molina P. (2014) Unmanned aerial systems for photogrammetry and remote sensing: A review. ISPRS Journal of Photogrammetry and Remote Sensing 92:79-97.

Coluccio K., Morgan L.K. (2019) A review of methods for measuring groundwater-surface water exchange in braided rivers. Hydrology and Earth System Sciences 23:4397-4417.

Coveney, S., Roberts K. (2017) Lightweight UAV digital elevation models and orthoimagery for environmental applications: data accuracy evaluation and potential for river flood risk modelling. International Journal of Remote Sensing 38(8-10):3159-3180.

Cracknell A.P. (2017) UAVs: regulations and law enforcement. International Journal of Remote Sensing 38:3054-3067. DOI: 10.1080/01431161.2017.1302115.

Dai E., Gasiewski A.J., Venkitasubramony A., Stachura M., Elston J. (2020) High Spatial Resolution Soil Moisture Mapping Using a Lobe Differencing Correlation Radiometer on a Small Unmanned Aerial System. IEEE Transactions on Geoscience and Remote Sensing:1-18. DOI: 10.1109/TGRS.2020.3005385.

Dal Sasso S.F., Pizarro A., Manfreda S. (2020) Metrics for the Quantification of Seeding Characteristics to Enhance Image Velocimetry Performance in Rivers. Remote Sensing 12:1789.

Dal Sasso S.F., Pizarro A., Pearce S., Maddock I., Manfreda S. (2021) Increasing LSPIV performances by exploiting the seeding distribution index at different spatial scales. Journal of Hydrology 598:126438.

Dal Sasso S.F., Pizarro A., Samela C., Mita L., Manfreda S. (2018) Exploring the optimal experimental setup for surface flow velocity measurements using PTV. Environmental Monitoring and Assessment 190:460. DOI: 10.1007/s10661-018-6848-3.

This article is protected by copyright. All rights reserved. 
Dao P.D., He Y., Proctor C. (2021) Plant drought impact detection using ultra-high spatial resolution hyperspectral images and machine learning. International Journal of Applied Earth Observation and Geoinformation 102:102364.

de Lima J.L.M.P., Abrantes J.R.C.B., Silva V.P., de Lima M.I.P., Montenegro A.A.A. (2014) Mapping Soil Surface Macropores Using Infrared Thermography: An Exploratory Laboratory Study. The Scientific World Journal 2014:845460. DOI: 10.1155/2014/845460.

De Michele C., Avanzi F., Passoni D., Barzaghi R., Pinto L., Dosso P., Ghezzi A., Gianatti R., Della Vedova G. (2016) Using a fixed-wing UAS to map snow depth distribution: an evaluation at peak accumulation. The Cryosphere 10:511-522. DOI: 10.5194/tc-10-511-2016.

Despax A., Le Coz J., Hauet A., Mueller D.S., Engel F.L., Blanquart B., Renard B., Oberg K.A. (2019) Decomposition of uncertainty sources in acoustic Doppler current profiler streamflow measurements using repeated measures experiments. Water Resources Research 55:7520-7540.

Dietrich J.T. (2017) Bathymetric Structure-from-Motion: extracting shallow stream bathymetry from multi-view stereo photogrammetry. Earth Surface Processes and Landforms 42:355-364. DOI: 10.1002/esp.4060.

Doi H., Akamatsu Y., Watanabe Y., Goto M., Inui R., Katano I., Nagano M., Takahara T., Minamoto T. (2017) Water sampling for environmental DNA surveys by using an unmanned aerial vehicle. Limnology and Oceanography: Methods 15:939-944.

Dramais G., Le Coz J., Camenen B., Hauet A. (2011) Advantages of a mobile LSPIV method for measuring flood discharges and improving stage-discharge curves. Journal of Hydroenvironment Research 5:301-312. DOI: https://doi.org/10.1016/j.jher.2010.12.005.

Drews P.L., Neto A.A., Campos M.F. (2014) Hybrid unmanned aerial underwater vehicle: Modeling and simulation, 2014 IEEE/RSJ International Conference on Intelligent Robots and Systems, IEEE. pp. 4637-4642.

Dugan J.P., Anderson S., Piotrowski C.C., Zuckerman S. (2013) Airborne infrared remote sensing of riverine currents. IEEE Transactions on Geoscience and Remote Sensing 52:3895-3907.

Dugdale S.J., Malcolm I.A., Hannah D.M. (2019) Drone-based Structure-from-Motion provides accurate forest canopy data to assess shading effects in river temperature models. Science of the Total Environment 678:326-340.

Dyer J., Moorhead R., Hathcock L. (2020) Identification and Analysis of Microscale Hydrologic Flood Impacts Using Unmanned Aerial Systems. Remote Sensing 12:1549.

Easterday K., Kislik C., Dawson T.E., Hogan S., Kelly M. (2019) Remotely sensed water limitation in vegetation: insights from an experiment with unmanned aerial vehicles (UAVs). Remote Sensing 11:1853.

Ehmann K., Kelleher C., Condon L.E. (2019) Monitoring turbidity from above: Deploying small unoccupied aerial vehicles to image in - stream turbidity. Hydrological Processes 33:1013-1021.

Ehsani R., Maja J.M. (2013) The rise of small UAVs in precision agriculture. Resource Magazine 20:1819.

Eitel J.U., Gessler P.E., Smith A.M., Robberecht R. (2006) Suitability of existing and novel spectral indices to remotely detect water stress in Populus spp. Forest Ecology and Management 229:170182.

Ellsäßer F., Stiegler C., Röll A., June T., Knohl A., Hölscher D. (2020) Predicting evapotranspiration from drone-based thermography-a method comparison in a tropical oil palm plantation. Biogeosciences Discussions:1-37.

Eltner A., Sardemann H., Grundmann J. (2020) Flow velocity and discharge measurement in rivers using terrestrial and unmanned-aerial-vehicle imagery. Hydrology and Earth System Sciences 24:14291445.

Erena M., Atenza J.F., García-Galiano S., Domínguez J.A., Bernabé J.M. (2019) Use of drones for the topo-bathymetric monitoring of the reservoirs of the Segura river basin. Water 11:445.

This article is protected by copyright. All rights reserved. 
Eskandari R., Mahdianpari M., Mohammadimanesh F., Salehi B., Brisco B., Homayouni S. (2020) Metaanalysis of Unmanned Aerial Vehicle (UAV) Imagery for Agro-environmental Monitoring Using Machine Learning and Statistical Models. Remote Sensing 12(21):3511.

Escobar Villanueva J.R., Iglesias Martínez L., Pérez Montiel J.I. (2019) DEM generation from fixed-wing UAV imaging and LiDAR-derived ground control points for flood estimations. Sensors 19(14):3205.

Favenza A., Imam R., Dovis F., Pini M. (2019) Detecting water using UAV-based GNSS-Reflectometry data and Artificial Intelligence, 2019 IEEE International Workshop on Metrology for Agriculture and Forestry (MetroAgriFor), IEEE. pp. 7-12.

Federal Aviation Administration (FAA). (2020) Press Release-U.S. Department of Transportation Announces Technology Partners for Remote ID Development. Available from: https://www.faa.gov/news/press_releases/news_story.cfm?newsId=24956 [Accessed 20 September 2020]

Food and Agriculture Organization of the United Nations. Crisis, Global Network Against Food (2020); FAO: Rome, Italy.

Flener C., Vaaja M., Jaakkola A., Krooks A., Kaartinen H., Kukko A., Kasvi E., Hyyppä H., Hyyppä J., Alho P. (2013) Seamless Mapping of River Channels at High Resolution Using Mobile LiDAR and UAV-Photography. Remote Sensing 5:6382-6407.

Flynn K.F., Chapra S.C. (2014) Remote sensing of submerged aquatic vegetation in a shallow non-turbid river using an unmanned aerial vehicle. Remote Sensing 6:12815-12836.

Fujita I., Muste M., Kruger A. (1998) Large-scale particle image velocimetry for flow analysis in hydraulic engineering applications. Journal of Hydraulic Research 36:397-414.

Gago J., Douthe C., Coopman R., Gallego P., Ribas-Carbo M., Flexas J., Escalona J., Medrano H. (2015) UAVs challenge to assess water stress for sustainable agriculture. Agricultural Water Management 153:9-19.

Gao A., Wu S., Wang F., Wu X., Xu P., Yu L., Zhu S. (2019) A newly developed unmanned aerial vehicle (UAV) imagery based technology for field measurement of water level. Water 11:124.

Ge X., Wang J., Ding J., Cao X., Zhang Z., Liu J., Li X. (2019) Combining UAV-based hyperspectral imagery and machine learning algorithms for soil moisture content monitoring. PeerJ 7:e6926.

Ge X., Ding J., Jin X., Wang J., Chen X., Li X., ... Xie B. (2021) Estimating Agricultural Soil Moisture Content through UAV-Based Hyperspectral Images in the Arid Region. Remote Sensing 13(8): 1562.

Genç O., Ardıçlığlu M., Ağıralioğlu N. (2015) Calculation of mean velocity and discharge using water surface velocity in small streams. Flow Measurement and Instrumentation 41:115-120. DOI: https://doi.org/10.1016/j.flowmeasinst.2014.10.013.

Giordano F., Mattei G., Parente C., Peluso F., Santamaria R. (2016) Integrating sensors into a marine drone for bathymetric 3D surveys in shallow waters. Sensors 16:41.

Gitelson A.A. (2004) Wide dynamic range vegetation index for remote quantification of biophysical characteristics of vegetation. Journal of Plant Physiology 161:165-173.

Golubkov G.V., Manzhelii M.I., Berlin A.A., Lushnikov A.A., Eppelbaum L.V. (2018) Effects of the Interaction of Microwave Radiation with the Atmosphere on the Passive Remote Sensing of the Earth's Surface: Problems and Solutions (Review). Russian Journal of Physical Chemistry B 12:725-748. DOI: 10.1134/S1990793118040061.

Gómez-Candón D., Virlet N., Labbé S., Jolivot A., Regnard J.L. (2016) Field phenotyping of water stress at tree scale by UAV-sensed imagery: new insights for thermal acquisition and calibration. Precision Agriculture 17(6):786-800.

Gray P.C., Ridge J.T., Poulin S.K., Seymour A.C., Schwantes A.M., Swenson J.J., Johnston D.W. (2018) Integrating drone imagery into high resolution satellite remote sensing assessments of estuarine environments. Remote Sensing 10:1257.

Guenther G.C., Cunningham A.G., LaRocque P.E., Reid D.J. (2000) Meeting the accuracy challenge in airborne bathymetry, National Oceanic Atmospheric Administration/Nesdis Silver Spring MD.

This article is protected by copyright. All rights reserved. 
Guimarães T.T., Veronez M.R., Koste E.C., Souza E.M., Brum D., Gonzaga L., Mauad F.F. (2019) Evaluation of regression analysis and neural networks to predict total suspended solids in water bodies from unmanned aerial vehicle images. Sustainability 11:2580.

Haddeland I., Heinke J., Biemans H., Eisner S., Flörke M., Hanasaki N., Konzmann M., Ludwig F., Masaki Y., Schewe J. (2014) Global water resources affected by human interventions and climate change. Proceedings of the National Academy of Sciences 111:3251-3256.

Ham G.W., Lee J.M., Bae K.H., Park H.G. (2019) A Study on Agricultural Drought Monitoring using Drone Thermal and Hyperspectral Sensor. Journal of the Korean Association of Geographic Information Studies 22(3):107-119.

Harder P., Pomeroy J.W., Helgason W.D. (2020) Improving sub-canopy snow depth mapping with unmanned aerial vehicles: lidar versus structure-from-motion techniques. The Cryosphere 14:1919-1935. DOI: 10.5194/tc-14-1919-2020.

Hardin P.J., Jensen R.R. (2011) Small-scale unmanned aerial vehicles in environmental remote sensing: Challenges and opportunities. GIScience \& Remote Sensing 48:99-111.

Hardisky M., Smart R., Klemas V. (1983) Seasonal spectral characteristics and aboveground biomass of the tidal marsh plant. Spartina-Alterniflora Photogrammetric Engineering and Remote Sensing 49:85-92.

Hashemi-Beni L., Jones J., Thompson G., Johnson C., Gebrehiwot A. (2018) Challenges and opportunities for UAV-based digital elevation model generation for flood-risk management: a case of Princeville, North Carolina. Sensors 18(11):3843.

Hassan-Esfahani L., Torres-Rua A., Jensen A., McKee M. (2015) Assessment of surface soil moisture using high-resolution multi-spectral imagery and artificial neural networks. Remote Sensing 7:2627-2646.

Hassan - Esfahani L., Torres - Rua A., Jensen A., Mckee M. (2017) Spatial root zone soil water content estimation in agricultural lands using bayesian - based artificial neural networks and high resolution visual, nir, and thermal imagery. Irrigation and Drainage 66:273-288.

Hoffmann H., Nieto H., Jensen R., Guzinski R., Zarco-Tejada P., Friborg T. (2016) Estimating evaporation with thermal UAV data and two-source energy balance models. Hydrology and Earth System Sciences 20(2):697-713.

Holland K.T., Lalejini D.M., Spansel S.D., Holman R.A. (2010) Littoral environmental reconnaissance using tactical imagery from unmanned aircraft systems, Ocean Sensing and Monitoring II, International Society for Optics and Photonics. pp. 767806.

Holman R.A., Holland K.T., Lalejini D.M., Spansel S.D. (2011) Surf zone characterization from Unmanned Aerial Vehicle imagery. Ocean dynamics 61:1927-1935.

Houtz D., Naderpour R., Schwank M. (2020) Portable L-Band Radiometer (PoLRa): Design and Characterization. Remote Sensing 12:2780.

Huang W.-C., Young C.-C., Liu W.-C. (2018a) Application of an Automated Discharge Imaging System and LSPIV during Typhoon Events in Taiwan. Water 10:280.

Huang Z.C., Yeh, C.Y., Tseng K.H., Hsu W.Y. (2018b) A UAV-RTK Lidar System for Wave and Tide Measurements in Coastal Zones. Journal of Atmospheric and Oceanic Technology 35(8):15571570.

Hunt E.R., Cavigelli M., Daughtry C.S., Mcmurtrey J.E., Walthall C.L. (2005) Evaluation of digital photography from model aircraft for remote sensing of crop biomass and nitrogen status. Precision Agriculture 6:359-378.

Hutchings A.M., Antler G., Wilkening J.V., Basu A., Bradbury H.J., Clegg J.A., Gorka M., Lin C.Y., Mills J.V., Pellerin A. (2019) Creek dynamics determine pond subsurface geochemical heterogeneity in east anglian (UK) salt marshes. Frontiers in Earth Science 7:41.

Huuskonen J., Oksanen T. (2018) Soil sampling with drones and augmented reality in precision agriculture. Computers and Electronics in Agriculture 154:25-35.

This article is protected by copyright. All rights reserved. 
Ichikawa K., Ebinuma T., Konda M., Yufu K. (2019) Low-Cost GNSS-R Altimetry on a UAV for WaterLevel Measurements at Arbitrary Times and Locations. Sensors 19:998.

Imam R., Pini M., Marucco G., Dominici F., Dovis F. (2020) UAV-Based GNSS-R for Water Detection as a Support to Flood Monitoring Operations: A Feasibility Study. Applied Sciences 10:210.

Jackisch R., Lorenz S., Zimmermann R., Möckel R., Gloaguen R. (2018) Drone-borne hyperspectral monitoring of acid mine drainage: An example from the Sokolov lignite district. Remote Sensing 10:385.

Jackson R., Pinter Jr P., Reginato R., Idso S. (1980) Hand-held radiometry: A set of notes developed for use at the Workshop of Hand-held radiometry.

Jacobs J.M., Hunsaker A.G., Sullivan F.B., Palace M., Burakowski E.A., Herrick C., Cho E. (2021) Snow depth mapping with unpiloted aerial system lidar observations: a case study in Durham, New Hampshire, United States. The Cryosphere 15(3):1485-1500.

Javernick L., Brasington J., Caruso B. (2014) Modeling the topography of shallow braided rivers using Structure-from-Motion photogrammetry. Geomorphology 213:166-182. DOI: https://doi.org/10.1016/j.geomorph.2014.01.006.

Jay S., Baret F., Dutartre D., Malatesta G., Héno S., Comar A., Weiss M., Maupas F. (2019) Exploiting the centimeter resolution of UAV multispectral imagery to improve remote-sensing estimates of canopy structure and biochemistry in sugar beet crops. Remote Sensing of Environment 231:110898. DOI: https://doi.org/10.1016/j.rse.2018.09.011.

Jeziorska J. (2019) UAS for Wetland Mapping and Hydrological Modeling. Remote Sensing 11:1997.

Jiang Z., Huete A.R., Didan K., Miura T. (2008) Development of a two-band enhanced vegetation index without a blue band. Remote Sensing of Environment 112:3833-3845.

Joshi D.R., Clay D.E., Smart A., Clay S.A., Kharel T.P., Mishra U. (2019a) Soil and land-use change sustainability in the Northern Great Plains of the USA.

Joshi D.R., Ulrich-Schad J., Wang T., Dunn B.H., Clay S.A., Bruggeman S.A., Clay D.E. (2019b) Grassland Retention in the North America Midwest after Periods of High Commodity Prices and Climate Variability. Soil Science Society of America Journal 83:1290-1298. DOI: 10.2136/sssaj2019.03.0090.

kalpa Gunarathna J., Munasinghe R. (2018) Development of a quad-rotor fixed-wing hybrid unmanned aerial vehicle, 2018 Moratuwa Engineering Research Conference (MERCon), IEEE. pp. 72-77.

Kamienski C., Soininen J.-P., Taumberger M., Dantas R., Toscano A., Salmon Cinotti T., Filev Maia R., Torre Neto A. (2019) Smart water management platform: Iot-based precision irrigation for agriculture. Sensors 19:276.

Kastridis A., Kirkenidis C., Sapountzis M. (2020) An integrated approach of flash flood analysis in ungauged Mediterranean watersheds using post-flood surveys and unmanned aerial vehicles. Hydrological Processes 34:4920-4939. DOI: https://doi.org/10.1002/hyp.13913.

Kellner J.R., Armston J., Birrer M., Cushman K., Duncanson L., Eck C., Falleger C., Imbach B., Král K., Krůček M. (2019) New opportunities for forest remote sensing through ultra-high-density drone lidar. Surveys in Geophysics 40:959-977.

Kim Y., Muste M., Hauet A., Krajewski W.F., Kruger A., Bradley A. (2008) Stream discharge using mobile large-scale particle image velocimetry: A proof of concept. Water Resources Research 44. DOI: https://doi.org/10.1029/2006WR005441.

Kinzel P.J., Legleiter C.J. (2019) sUAS-Based Remote Sensing of River Discharge Using Thermal Particle Image Velocimetry and Bathymetric Lidar. Remote Sensing 11:2317.

Kislik C., Dronova I., Kelly M. (2018) UAVs in support of algal bloom research: a review of current applications and future opportunities. Drones 2:35.

Klemas V.V. (2015) Coastal and environmental remote sensing from unmanned aerial vehicles: An overview. Journal of Coastal Research 31:1260-1267.

Kolokoussis P., Karathanassi V., Rokos D., Argialas D., Karageorgis A.P., Georgopoulos D. (2011) Integrating thermal and hyperspectral remote sensing for the detection of coastal springs and submarine groundwater discharges. International Journal of Remote Sensing 32:8231-8251.

This article is protected by copyright. All rights reserved. 
Koparan C., Koc A.B., Privette C.V., Sawyer C.B. (2018) In situ water quality measurements using an unmanned aerial vehicle (UAV) system. Water 10:264.

Koutalakis P., Tzoraki O., Zaimes G. (2019) UAVs for hydrologic scopes: application of a low-cost UAV to estimate surface water velocity by using three different image-based methods. Drones 3:14.

Kum B.-C., Shin D.-H., Jang S., Lee S.Y., Lee J.H., Moh T., Lim D.G., Do J.-D., Cho J.H. (2020) Application of Unmanned Surface Vehicles in Coastal Environments: Bathymetric Survey using a Multibeam Echosounder. Journal of Coastal Research 95:1152-1156.

Kumar S.V., Dirmeyer P.A., Peters-Lidard C.D., Bindlish R., Bolten J. (2018) Information theoretic evaluation of satellite soil moisture retrievals. Remote Sensing of Environment 204:392-400. DOI: https://doi.org/10.1016/j.rse.2017.10.016.

Kustas W.P., Anderson M.C., Alfieri J.G., Knipper K., Torres-Rua A., Parry, C.K., ... \& Hain, C. (2018) The grape remote sensing atmospheric profile and evapotranspiration experiment. Bulletin of the American Meteorological Society 99(9):1791-1812.

Kustas W.P., Alfieri J.G., Nieto H., Gao F., Anderson M.C., Prueger J.H., Wilson T.G. (2019) Utility of the two-source energy balance model TSEB in vine and inter-row flux partitioning over the growing season. Irrigation Science 37(3):375-388. https://doi.org/10.1007/s00271-018-0586-8

Kwon Y.S., Pyo J., Kwon Y.-H., Duan H., Cho K.H., Park Y. (2020) Drone-based hyperspectral remote sensing of cyanobacteria using vertical cumulative pigment concentration in a deep reservoir. Remote Sensing of Environment 236:111517. DOI: https://doi.org/10.1016/j.rse.2019.111517.

Lally H., O'Connor I., Jensen O., Graham C. (2019) Can drones be used to conduct water sampling in aquatic environments? A review. Science of the Total Environment 670:569-575.

Lally H., O'Connor I., Broderick L., Broderick M., Jensen O., Graham C. (2020) Assessing the Potential of Drones to Take Water Samples and Physicochemical Data from Open Lakes. EPA Research Programme 2014-2020.

Langhammer J., Vacková T. (2018) Detection and mapping of the geomorphic effects of flooding using UAV photogrammetry. Pure and Applied Geophysics 175(9):3223-3245.

Langhammer J., Bernsteinová J., Miřijovský J. (2017) Building a high-precision 2D hydrodynamic flood model using UAV photogrammetry and sensor network monitoring. Water 9(11):861.

Larson M.D., Simic Milas A., Vincent R.K., Evans J.E. (2018) Multi-depth suspended sediment estimation using high-resolution remote-sensing UAV in Maumee River, Ohio. International Journal of Remote Sensing 39:5472-5489.

Le Coz J., Hauet A., Pierrefeu G., Dramais G., Camenen B. (2010) Performance of image-based velocimetry (LSPIV) applied to flash-flood discharge measurements in Mediterranean rivers. Journal of Hydrology 394:42-52. DOI: https://doi.org/10.1016/j.jhydrol.2010.05.049.

Lee E., Kang K.M., Hyun S.P., Lee K.Y., Yoon H., Kim S.H., Kim Y., Xu Z., Kim D.j., Koh D.C. (2016a) Submarine groundwater discharge revealed by aerial thermal infrared imagery: a case study on Jeju Island, Korea. Hydrological Processes 30:3494-3506.

Lee E., Yoon H., Hyun S.P., Burnett W.C., Koh D.C., Ha K., Kim D.j., Kim Y., Kang K.m. (2016b) Unmanned aerial vehicles (UAVs) - based thermal infrared (TIR) mapping, a novel approach to assess groundwater discharge into the coastal zone. Limnology and Oceanography: Methods 14:725-735.

Legleiter C.J., Kinzel P.J., Nelson J.M. (2017) Remote measurement of river discharge using thermal particle image velocimetry (PIV) and various sources of bathymetric information. Journal of Hydrology 544:490-506.

Legleiter C.J., Kinzel P.J. (2020) Inferring surface flow velocities in sediment-laden Alaskan rivers from optical image sequences acquired from a helicopter. Remote Sensing 12(8):1282.

Leitão J.P., Peña-Haro S., Lüthi B., Scheidegger A., de Vitry M.M. (2018) Urban overland runoff velocity measurement with consumer-grade surveillance cameras and surface structure image velocimetry. Journal of Hydrology 565:791-804.

This article is protected by copyright. All rights reserved. 
Lejot J., Delacourt C., Piégay H., Fournier T., Trémélo M.-L., Allemand P. (2007) Very high spatial resolution imagery for channel bathymetry and topography from an unmanned mapping controlled platform. Earth Surface Processes and Landforms 32:1705-1725. DOI: 10.1002/esp.1595.

Lewis Q.W., Edmonds D.A., Yanites B.J. (2020) Integrated UAS and LiDAR reveals the importance of land cover and flood magnitude on the formation of incipient chute holes and chute cutoff development. Earth Surface Processes and Landforms 45:1441-1455.

Lewis Q.W., Lindroth E.M., Rhoads B.L. (2018) Integrating unmanned aerial systems and LSPIV for rapid, cost-effective stream gauging. Journal of Hydrology 560:230-246.

Liang J., Zhang J., Ma Y., Zhang C.-Y. (2017) Derivation of bathymetry from high-resolution optical satellite imagery and USV sounding data. Marine Geodesy 40:466-479.

Liu, P., Chen, A.Y., Huang, Y.N., Han, J. Y., Lai, J.S., Kang, S. C., ... Tsai, M.H. (2014). A review of rotorcraft unmanned aerial vehicle (UAV) developments and applications in civil engineering. Smart Structures and Systems 13(6):1065-1094.

Lowe M.K., Adnan F.A.F., Hamylton S.M., Carvalho R.C., Woodroffe C.D. (2019) Assessing reef-island shoreline change using UAV-derived orthomosaics and digital surface models. Drones 3:44.

Lu B., He Y. (2018) Optimal spatial resolution of Unmanned Aerial Vehicle (UAV)-acquired imagery for species classification in a heterogeneous grassland ecosystem. GIScience \& Remote Sensing 55:205-220. DOI: 10.1080/15481603.2017.1408930.

Ludovisi, R., Tauro, F., Salvati, R., Khoury, S., Mugnozza Scarascia, G., Harfouche, A. (2017). UAVbased thermal imaging for high-throughput field phenotyping of black poplar response to drought. Frontiers in Plant Science 8:1681.

Ma Z., Feng J., Yang J. (2018) Research on vertical air-water trans-media control of hybrid unmanned aerial underwater vehicles based on adaptive sliding mode dynamical surface control. International Journal of Advanced Robotic Systems 15:1729881418770531.

Mallet C., Bretar F. (2009) Full-waveform topographic lidar: State-of-the-art. ISPRS Journal of Photogrammetry and Remote Sensing 64:1-16.

Mancini F., Dubbini M., Gattelli M., Stecchi F., Fabbri S., Gabbianelli G. (2013) Using Unmanned Aerial Vehicles (UAV) for High-Resolution Reconstruction of Topography: The Structure from Motion Approach on Coastal Environments. Remote Sensing 5:6880-6898.

Mandlburger G., Pfennigbauer M., Schwarz R., Flöry S., Nussbaumer L. (2020) Concept and Performance Evaluation of a Novel UAV-Borne Topo-Bathymetric LiDAR Sensor. Remote Sensing 12:986.

Mandlburger G., Pfennigbauer M., Wieser M., Riegl U., Pfeifer N. (2016) Evaluation of a novel UAVborne Topo-bathymetric laser profiler. International Archives of Photogrammetry, Remote Sensing and Spatial Information Sciences XLI-B1:933-939. DOI: 10.5194/isprs-archives-XLIB1-933-2016.

Manfreda S., Dvorak P., Mullerova J., Herban S., Vuono P., Arranz Justel J.J., Perks M. (2019) Assessing the Accuracy of Digital Surface Models Derived from Optical Imagery Acquired with Unmanned Aerial Systems. Drones 3:15.

Manfreda S., McCabe M.F., Miller P.E., Lucas R., Pajuelo Madrigal V., Mallinis G., Ben Dor E., Helman D., Estes L., Ciraolo G. (2018) On the use of unmanned aerial systems for environmental monitoring. Remote Sensing 10:641.

McCabe M.F., Rodell M., Alsdorf D.E., Miralles D.G., Uijlenhoet R., Wagner W., Lucieer A., Houborg R., Verhoest N.E.C., Franz T.E., Shi J., Gao H., Wood E.F. (2017) The Future of Earth Observation in Hydrology. Hydrology and Earth System Sciences 21:3879-3914. DOI: 10.5194/hess-21-3879-2017.

McDonald W. (2019) Drones in urban stormwater management: A review and future perspectives. Urban Water Journal 16:505-518.

This article is protected by copyright. All rights reserved. 
Melcher N.B., Costa J.E., Haeni F.P., Cheng R.T., Thurman E.M., Buursink M., Spicer K.R., Hayes E., Plant W.J., Keller W.C., Hayes K. (2002) River discharge measurements by using helicoptermounted radar. Geophysical Research Letters 29:41-1-41-4. DOI: 10.1029/2002gl015525.

Miziński B., Niedzielski T. (2017) Fully-automated estimation of snow depth in near real time with the use of unmanned aerial vehicles without utilizing ground control points. Cold Regions Science and Technology 138:63-72. DOI: https://doi.org/10.1016/j.coldregions.2017.03.006.

Mohamad N., Abdul Khanan M.F., Ahmad A., Md Din A.H., Shahabi H. (2019) Evaluating water level changes at different tidal phases using UAV photogrammetry and GNSS vertical data. Sensors 19:3778.

Moramarco T., Barbetta S., Bjerklie D.M., Fulton J.W., Tarpanelli A. (2019) River Bathymetry Estimate and Discharge Assessment from Remote Sensing. Water Resources Research 55:6692-6711. DOI: https://doi.org/10.1029/2018WR024220.

Moramarco T., Singh V.P. (2010) Formulation of the Entropy Parameter Based on Hydraulic and Geometric Characteristics of River Cross Sections. Journal of Hydrologic Engineering 15:852858. DOI: doi:10.1061/(ASCE)HE.1943-5584.0000255.

Morgan B.J., Stocker M.D., Valdes-Abellan J., Kim M.S., Pachepsky Y. (2020) Drone-based imaging to assess the microbial water quality in an irrigation pond: A pilot study. Science of the Total Environment 716:135757.

Muhadi N.A., Abdullah A.F., Bejo S.K., Mahadi M.R., Mijic A. (2020) The Use of LiDAR-Derived DEM in Flood Applications: A Review. Remote Sensing 12:2308.

Navarro A., Young M., Allan B., Carnell P., Macreadie P., Ierodiaconou D. (2020) The application of Unmanned Aerial Vehicles (UAVs) to estimate above-ground biomass of mangrove ecosystems. Remote Sensing of Environment 242:111747. DOI: https://doi.org/10.1016/j.rse.2020.111747.

Neill P.O., Entekhabi D., Njoku E., Kellogg K. (2010) The NASA Soil Moisture Active Passive (SMAP) mission: Overview, 2010 IEEE International Geoscience and Remote Sensing Symposium. pp. 3236-3239.

Nguyen L.H., Joshi D.R., Clay D.E., Henebry G.M. (2020) Characterizing land cover/land use from multiple years of Landsat and MODIS time series: A novel approach using land surface phenology modeling and random forest classifier. Remote Sensing of Environment 238:111017.

Nguyen L.H., Joshi D.R., Henebry G.M. (2019) Improved change detection with trajectory-based approach: Application to quantify cropland expansion in South Dakota. Land 8:57.

Nieto H., Kustas W.P., Torres-Rúa A., Alfieri J.G., Gao F., Anderson M.C., White W.A., Song L., del Mar Alsina M., Prueger J.H., McKee M., Elarab M., McKee L.G. (2019a) Evaluation of TSEB turbulent fluxes using different methods for the retrieval of soil and canopy component temperatures from UAV thermal and multispectral imagery. Irrigation Science 37(3):389-406. https://doi.org/10.1007/s00271-018-0585-9

Ore J.P., Elbaum S., Burgin A., Detweiler C. (2015) Autonomous aerial water sampling. Journal of Field Robotics 32:1095-1113.Özcan O., Akay S.S. (2018, July) Modeling Morphodynamic Processes in Meandering Rivers with UAV-Based Measurements. In IGARSS 2018-2018 IEEE International Geoscience and Remote Sensing Symposium (pp. 7886-7889). IEEE.

Pai H., Malenda H.F., Briggs M.A., Singha K., González-Pinzón R., Gooseff M.N., Tyler S.W., Team t.A. (2017) Potential for Small Unmanned Aircraft Systems Applications for Identifying Groundwater-Surface Water Exchange in a Meandering River Reach. Geophysical Research Letters 44:11,868-11,877. DOI: 10.1002/2017g1075836.

Pajares G. (2015) Overview and current status of remote sensing applications based on unmanned aerial vehicles (UAVs). Photogrammetric Engineering \& Remote Sensing 81:281-330.

Paruta A., Ciraolo G., Capodici F., Manfreda S., Dal Sasso S.F., Zhuang R., Romano N., Nasta P., BenDor E., Francos N. (2020) A Geostatistical Approach to Map Near-Surface Soil Moisture Through Hyperspatial Resolution Thermal Inertia. IEEE Transactions on Geoscience and Remote Sensing.

This article is protected by copyright. All rights reserved. 
Pearce S., Ljubičić R., Peña-Haro S., Perks M., Tauro F., Pizarro A., Dal Sasso S.F., Strelnikova D., Grimaldi S., Maddock I. (2020) An evaluation of image velocimetry techniques under low flow conditions and high seeding densities using unmanned aerial systems. Remote Sensing 12:232.

Perks M., Russell A., Large A. (2016) Technical Note: Advances in flash flood monitoring using UAVs. Hydrology and Earth System Sciences Discussion 20:4005-4015.

Perks M.T. (2020) KLT-IV v1.0: image velocimetry software for use with fixed and mobile platforms. Geosci. Model Dev. 13:6111-6130. DOI: 10.5194/gmd-13-6111-2020.

Perks M.T., Dal Sasso S.F., Hauet A., Jamieson E., Le Coz J., Pearce S., Peña-Haro S., Pizarro A., Strelnikova D., Tauro F., Bomhof J., Grimaldi S., Goulet A., Hortobágyi B., Jodeau M., Käfer S., Ljubičić R., Maddock I., Mayr P., Paulus G., Pénard L., Sinclair L., Manfreda S. (2020) Towards harmonisation of image velocimetry techniques for river surface velocity observations. Earth System Science Data 12:1545-1559. DOI: 10.5194/essd-12-1545-2020.

Pingel, T.J., Saavedra, A., Cobo, L., 2021. Deriving Land and Water Surface Elevations in the Northeastern Yucatán Peninsula Using PPK GPS and UAV-Based Structure from Motion. Pap. Applied Geography https://doi.org/10.1080/23754931.2021.1871937

Pizarro A., Dal Sasso S.F., Manfreda S. (2020a) Refining image-velocimetry performances for streamflow monitoring: Seeding metrics to errors minimization. Hydrological Processes 34:51675175. DOI: https://doi.org/10.1002/hyp.13919.

Pizarro A., Dal Sasso S.F., Perks M.T., Manfreda S. (2020b) Identifying the optimal spatial distribution of tracers for optical sensing of stream surface flow. Hydrology and Earth System Sciences 24:5173-5185. DOI: 10.5194/hess-24-5173-2020.

Plant W.J., Keller W.C., Hayes K. (2005) Measurement of river surface currents with coherent microwave systems. IEEE Transactions on Geoscience and Remote Sensing 43:1242-1257. DOI: 10.1109/TGRS.2005.845641.

Poblete T., Ortega-Farías S., Moreno M.A., Bardeen M. (2017) Artificial neural network to predict vine water status spatial variability using multispectral information obtained from an unmanned aerial vehicle (UAV). Sensors 17:2488.

Polcher J., Piles M., Gelati E., Barella-Ortiz A., Tello M. (2016) Comparing surface-soil moisture from the SMOS mission and the ORCHIDEE land-surface model over the Iberian Peninsula. Remote Sensing of Environment 174:69-81. DOI: https://doi.org/10.1016/j.rse.2015.12.004.

Qi J., Chehbouni A., Huete A.R., Kerr Y.H., Sorooshian S. (1994) A modified soil adjusted vegetation index. Remote Sensing of Environment 48:119-126. DOI: https://doi.org/10.1016/00344257(94)90134-1.

Qi S., Wang F., Jing L. (2018) Unmanned aircraft system pilot/operator qualification requirements and training study, MATEC Web of Conferences, EDP Sciences. pp. 03006.

Quiquerez A., Chevigny E., Allemand P., Curmi P., Petit C., Grandjean P. (2014) Assessing the impact of soil surface characteristics on vineyard erosion from very high spatial resolution aerial images (Côte de Beaune, Burgundy, France). Catena 116:163-172.

Raffel M., Willert C.E., Scarano F., Kähler C.J., Wereley S.T., Kompenhans J. (2018) Particle image velocimetry: a practical guide Springer.

Rakha T., Gorodetsky A. (2018) Review of Unmanned Aerial System (UAS) applications in the built environment: Towards automated building inspection procedures using drones. Automation in Construction 93:252-264. DOI: https://doi.org/10.1016/j.autcon.2018.05.002.

Resop J.P., Lehmann L., Hession W.C. (2019) Drone Laser Scanning for Modeling Riverscape Topography and Vegetation: Comparison with Traditional Aerial Lidar. Drones 3:35.Rhee D.S., Kim Y.D., Kang B., Kim D. (2017) Applications of unmanned aerial vehicles in fluvial remote sensing: An overview of recent achievements. KSCE Journal of Civil Engineering 22: 588-602.

Ridolfi E., Manciola P. (2018) Water Level Measurements from Drones: A Pilot Case Study at a Dam Site. Water 10:297.

Rondeaux G., Steven M., Baret F. (1996) Optimization of soil-adjusted vegetation indices. Remote Sensing of Environment 55:95-107.Rostom N.G., Shalaby A.A., Issa Y.M., Afifi A.A. (2017)

This article is protected by copyright. All rights reserved. 
Evaluation of Mariut Lake water quality using Hyperspectral Remote Sensing and laboratory works. The Egyptian Journal of Remote Sensing and Space Science 20:S39-S48.

Roujean J.-L., Breon F.-M. (1995) Estimating PAR absorbed by vegetation from bidirectional reflectance measurements. Remote Sensing of Environment 51:375-384.

Roussel N., Darrozes J., Ha C., Boniface K., Frappart F., Ramillien G., Gavart M., Van de Vyvere L., Desenfans O., Baup F. (2016) Multi-scale volumetric soil moisture detection from GNSS SNR data: Ground-based and airborne applications, 2016 IEEE Metrology for Aerospace (MetroAeroSpace), IEEE. pp. 573-578.

Saeed A.S., Younes A.B., Cai C., Cai G. (2018) A survey of hybrid unmanned aerial vehicles. Progress in Aerospace Sciences 98:91-105.Salmoral G., Rivas Casado M., Muthusamy M., Butler D., Menon P.P., Leinster P. (2020) Guidelines for the use of unmanned aerial systems in flood emergency response. Water 12(2):521.

Şerban G., Rus I., Vele D., Breţcan P., Alexe M., Petrea D. (2016) Flood-prone area delimitation using UAV technology, in the areas hard-to-reach for classic aircrafts: case study in the north-east of Apuseni Mountains, Transylvania. Natural Hazards 82(3):1817-1832.

Shi L., Qiu Y., Shi J., Zhao S. (2015) Atmospheric influences analysis in passive microwave remote sensing, 2015 IEEE International Geoscience and Remote Sensing Symposium (IGARSS). pp. 2334-2337.

Siewert M.B., Olofsson J. (2020) Scale-dependency of Arctic ecosystem properties revealed by UAV. Environmental Research Letters 15:094030. DOI: 10.1088/1748-9326/aba20b.

Sishodia R., Ray R.L., and Singh S. (2020) Applications of remote sensing in precision agriculture: A review. Remote Sensing 12(19): 3136. https://doi.org/10.3390/rs12193136

Specht M., Specht C., Szafran M., Makar A., Dąbrowski P., Lasota H., Cywiński P. (2020) The Use of USV to Develop Navigational and Bathymetric Charts of Yacht Ports on the Example of National Sailing Centre in Gdańsk. Remote Sensing 12:2585.Staines C., Pomeroy, J. W. (2019) UAV LiDAR for Measuring Snow Interception in Forests. 76th Eastern Snow Conference, Fairlee, Vermont, USA

Starek M.J., Giessel J. (2017) Fusion of UAS-based structure-from-motion and optical inversion for seamless topo-bathymetric mapping, 2017 IEEE International Geoscience and Remote Sensing Symposium (IGARSS), IEEE. pp. 2999-3002.

Stark B., Zhao T., Chen Y. (2016, June) An analysis of the effect of the bidirectional reflectance distribution function on remote sensing imagery accuracy from small unmanned aircraft systems. In 2016 International Conference on Unmanned Aircraft Systems (ICUAS) (pp. 1342-1350). IEEE.

Still C., Powell R., Aubrecht D., Kim Y., Helliker B., Roberts D., Richardson A.D., Goulden M. (2019) Thermal imaging in plant and ecosystem ecology: applications and challenges. Ecosphere 10:e02768. DOI: 10.1002/ecs2.2768.

Stimson H.C., Breshears D.D., Ustin S.L., Kefauver S.C. (2005) Spectral sensing of foliar water conditions in two co-occurring conifer species: Pinus edulis and Juniperus monosperma. Remote Sensing of Environment 96:108-118.

Stumpf A., Augereau E., Delacourt C., Bonnier J. (2016) Photogrammetric discharge monitoring of small tropical mountain rivers: A case study at Rivière des Pluies, Réunion Island. Water Resources Research 52:4550-4570. DOI: https://doi.org/10.1002/2015WR018292.

Suárez L., Zarco-Tejada P.J., Sepulcre-Cantó G., Pérez-Priego O., Miller J.R., Jiménez-Muñoz J.C., Sobrino J. (2008) Assessing canopy PRI for water stress detection with diurnal airborne imagery. Remote Sensing of Environment 112:560-575. DOI: https://doi.org/10.1016/j.rse.2007.05.009.

Sullivan J.M. (2006) Evolution or revolution? the rise of UAVs. IEEE Technology and Society Magazine 25:43-49. DOI: 10.1109/MTAS.2006.1700021.

Sun S.-H., Chuang W.-L., Chang K.-A., Young Kim J., Kaihatu J., Huff T., Feagin R. (2019) Imagingbased nearshore bathymetry measurement using an unmanned aircraft system. Journal of Waterway, Port, Coastal, and Ocean Engineering 145:04019002.

This article is protected by copyright. All rights reserved. 
Tamminga A., Hugenholtz C., Eaton B., Lapointe M. (2015) Hyperspatial Remote Sensing of Channel Reach Morphology and Hydraulic Fish Habitat Using an Unmanned Aerial Vehicle (UAV): A First Assessment in the Context of River Research and Management. River Research and Applications 31:379-391. DOI: 10.1002/rra.2743.

Tauro F., Grimaldi S. (2017) Ice dices for monitoring stream surface velocity. Journal of Hydroenvironment Research 14:143-149.

Tauro F., Pagano C., Phamduy P., Grimaldi S., Porfiri M. (2015) Large-scale particle image velocimetry from an unmanned aerial vehicle. IEEE/ASME Transactions on Mechatronics 20:3269-3275.

Tauro F., Petroselli A., Arcangeletti E. (2016a) Assessment of drone-based surface flow observations. Hydrological Processes 30:1114-1130. DOI: 10.1002/hyp.10698.

Tauro F., Porfiri M., Grimaldi S. (2016b) Surface flow measurements from drones. Journal of Hydrology 540:240-245. DOI: https://doi.org/10.1016/j.jhydrol.2016.06.012.

Tauro F., Salvatori S. (2017) Surface flows from images: ten days of observations from the Tiber River gauge-cam station. Hydrology Research 48:646-655.

Tauro F., Selker J., Van De Giesen N., Abrate T., Uijlenhoet R., Porfiri M., Manfreda S., Caylor K., Moramarco T., Benveniste J. (2018) Measurements and Observations in the XXI century (MOXXI): innovation and multi-disciplinarity to sense the hydrological cycle. Hydrological Sciences Journal 63:169-196.

Templin T., Popielarczyk D., Kosecki R. (2018) Application of Low-Cost Fixed-Wing UAV for Inland Lakes Shoreline Investigation. Pure and Applied Geophysics 175:3263-3283. DOI: 10.1007/s00024-017-1707-7.

Terada A., Morita Y., Hashimoto T., Mori T., Ohba T., Yaguchi M., Kanda W. (2018) Water sampling using a drone at Yugama crater lake, Kusatsu-Shirane volcano, Japan. Earth, Planets and Space 70:64. DOI: 10.1186/s40623-018-0835-3.

Thielicke W., Stamhuis E.J. (2014) PIVlab-time-resolved digital particle image velocimetry tool for MATLAB. Published under the BSD license, programmed with MATLAB 7:R14.

Thomas R., Lehmann K., Nguyen H., Jackson D., Wolfe D., Ramanathan V. (2012) Measurement of turbulent water vapor fluxes using a lightweight unmanned aerial vehicle system. Atmospheric Measurement Techniques 5:243-257.

Thorp K.R., Thompson A.L., Harders S.J., French A.N., Ward R.W. (2018) High-Throughput Phenotyping of Crop Water Use Efficiency via Multispectral Drone Imagery and a Daily Soil Water Balance Model. Remote Sensing 10:1682.

Tilahun T. (2019) High-resolution mapping of subsurface tile drainage in agricultural fields using an Unmanned Aerial System (UAS). Doctoral Dissertation, Illinois State University.

Tosi F., Rocca M., Aleotti F., Poggi M., Mattoccia S., Tauro F., ... Grimaldi S. (2020) Enabling imagebased streamflow monitoring at the edge. Remote Sensing 12(12): 2047.

Troglia Gamba M., Marucco G., Pini M., Ugazio S., Falletti E., Lo Presti L. (2015) Prototyping a GNSSBased Passive Radar for UAVs: An Instrument to Classify the Water Content Feature of Lands. Sensors 15:28287-28313.

Vautherin J., Rutishauser S., Schneider-Zapp K., Choi H.F., Chovancova V., Glass A., Strecha C. (2016) Photogrammetric accuracy and modeling of rolling shutter cameras. ISPRS Annals of Photogrammetry, Remote Sensing \& Spatial Information Sciences 3.

Vélez-Nicolás M., García-López S., Barbero L., Ruiz-Ortiz V., Sánchez-Bellón Á. (2021) Applications of Unmanned Aerial Systems (UASs) in Hydrology: A Review. Remote Sensing 13(7), 1359.

Vivoni E.R., Rango A., Anderson C.A., Pierini N.A., Schreiner-McGraw A.P., Saripalli S., Laliberte A.S. (2014) Ecohydrology with unmanned aerial vehicles. Ecosphere 5:art130. DOI: 10.1890/es1400217.1.

Wang S., Baum A., Zarco-Tejada P.J., Dam-Hansen C., Thorseth A., Bauer-Gottwein P., Bandini F., Garcia M. (2019a) Unmanned Aerial System multispectral mapping for low and variable solar irradiance conditions: Potential of tensor decomposition. ISPRS Journal of Photogrammetry and Remote Sensing 155:58-71. DOI: https://doi.org/10.1016/j.isprsjprs.2019.06.017.

This article is protected by copyright. All rights reserved. 
Wang S., Garcia M., Bauer-Gottwein P., Jakobsen J., Zarco-Tejada P.J., Bandini F., Paz V.S., Ibrom A. (2019b) High spatial resolution monitoring land surface energy, water and CO2 fluxes from an Unmanned Aerial System. Remote Sensing of Environment 229:14-31. DOI: https://doi.org/10.1016/j.rse.2019.03.040.

Wang S., Garcia M., Ibrom A., Bauer-Gottwein P. (2020) Temporal interpolation of land surface fluxes derived from remote sensing-results with an unmanned aerial system. Hydrology and Earth System Sciences 24(7):3643-3661.

Wang S., Garcia M., Ibrom A., Jakobsen J., Josef Köppl C., Mallick K., Looms M.C., Bauer-Gottwein P. (2018) Mapping Root-Zone Soil Moisture Using a Temperature-Vegetation Triangle Approach with an Unmanned Aerial System: Incorporating Surface Roughness from Structure from Motion. Remote Sensing 10:1978.

Wei L., Huang C., Zhong Y., Wang Z., Hu X., Lin L. (2019). Inland waters suspended solids concentration retrieval based on PSO-LSSVM for UAV-borne hyperspectral remote sensing imagery. Remote Sensing 11(12):1455.

Welber M., Le Coz J., Laronne J.B., Zolezzi G., Zamler D., Dramais G., Hauet A., Salvaro M. (2016) Field assessment of noncontact stream gauging using portable surface velocity radars (SVR). Water Resources Research 52:1108-1126. DOI: https://doi.org/10.1002/2015WR017906.

Westaway R.M. (2001) Remote sensing of clear-water, shallow, gravel-bed rivers using digital photogrammetry, Photogrammetric Engineering and Remote Sensing, Photogrammetric Engineering and Remote Sensing. pp. 11.

Westaway R.M., Lane S.N., Hicks D.M. (2000) The development of an automated correction -procedure for digital photogrammetry for the study of wide, shallow, gravel-bed rivers. Earth Surface Processes and Landforms 25:209-226. DOI: 10.1002/(sici)1096-9837(200002)25:2<209::Aidesp84>3.0.Co;2-z.

Wester-Ebbinghaus W. (1980) Aerial photography by radio controlled model helicopter. The Photogrammetric Record 10:85-92. DOI: 10.1111/j.1477-9730.1980.tb00006.x.

Wigmore O., Mark B. (2018) High altitude kite mapping: evaluation of kite aerial photography (KAP) and structure from motion digital elevation models in the Peruvian Andes. International Journal of Remote Sensing 39:4995-5015.

Wigmore O., Mark B., McKenzie J., Baraer M., Lautz L. (2019) Sub-metre mapping of surface soil moisture in proglacial valleys of the tropical Andes using a multispectral unmanned aerial vehicle. Remote Sensing of Environment 222: 104-118.

Woodget A.S., Austrums R., Maddock I.P., Habit E. (2017) Drones and digital photogrammetry: from classifications to continuums for monitoring river habitat and hydromorphology. WIREs Water 4:e1222. DOI: 10.1002/wat2.1222.

Woodget A.S., Carbonneau P.E., Visser F., Maddock I.P. (2015) Quantifying submerged fluvial topography using hyperspatial resolution UAS imagery and structure from motion photogrammetry. Earth Surface Processes and Landforms 40:47-64. DOI: 10.1002/esp.3613.

Wu D., Li R., Zhang F., Liu J. (2019) A review on drone-based harmful algae blooms monitoring. Environmental Monitoring and Assessment 191(4):1-11.

Wu K., Rodriguez G.A., Zajc M., Jacquemin E., Clément M., De Coster A., Lambot S. (2019) A new drone-borne GPR for soil moisture mapping. Remote Sensing of Environment 235:111456. DOI: https://doi.org/10.1016/j.rse.2019.111456.

Xue J., Su B. (2017) Significant Remote Sensing Vegetation Indices: A Review of Developments and Applications. Journal of Sensors 2017:1353691. DOI: 10.1155/2017/1353691.

Yang S.-Q., Tan S.-K., Lim S.-Y. (2004) Velocity Distribution and Dip-Phenomenon in Smooth Uniform Open Channel Flows. Journal of Hydraulic Engineering 130:1179-1186. DOI: doi:10.1061/(ASCE)0733-9429(2004)130:12(1179).

Yang S., Wang J., Wang P., Gong T., Liu H. (2019) Low Altitude Unmanned Aerial Vehicles (UAVs) and Satellite Remote Sensing Are Used to Calculated River Discharge Attenuation Coefficients of Ungauged Catchments in Arid Desert. Water 11:2633.

This article is protected by copyright. All rights reserved. 
Yalcin E. (2019) Two-dimensional hydrodynamic modelling for urban flood risk assessment using unmanned aerial vehicle imagery: A case study of Kirsehir, Turkey. Journal of Flood Risk Management 12:e12499.

Yao H., Qin R., Chen X. (2019) Unmanned Aerial Vehicle for Remote Sensing Applications-A Review. Remote Sensing 11:1443.

Yasin J.N., Mohamed S.A., Haghbayan M.-H., Heikkonen J., Tenhunen H., Plosila J. (2020) Unmanned Aerial Vehicles (UAVs): Collision Avoidance Systems and Approaches. IEEE Access 8:105139105155.

Yorke T.H., Oberg K.A. (2002) Measuring river velocity and discharge with acoustic Doppler profilers. Flow Measurement and Instrumentation 13:191-195.

Zakaria S., Mahadi M.R., Abdullah A.F., Abdan K. (2018, March) Aerial platform reliability for flood monitoring under various weather conditions: A review. In GeoInformation for Disaster Management Conference (pp. 295-314). Springer, Cham.

Zhang C., Kovacs J.M. (2012) The application of small unmanned aerial systems for precision agriculture: a review. Precision Agriculture 13:693-712.

Zhang L., Niu Y., Zhang H., Han W., Li G., Tang J., Peng X. (2019) Maize canopy temperature extracted from UAV thermal and RGB imagery and its application in water stress monitoring. Frontiers in Plant Science 10:1270.

Zhang Y., Wu L., Ren H., Liu Y., Zheng Y., Liu Y., Dong J. (2020) Mapping water quality parameters in urban rivers from hyperspectral images using a new self-adapting selection of multiple artificial neural networks. Remote Sensing 12(2):336.

Zhao T., Stark B., Chen Y., Ray A., Doll D. (2016) More Reliable Crop Water Stress Quantification Using Small Unmanned Aerial Systems (sUAS). IFAC-PapersOnLine 49:409-414. DOI: https://doi.org/10.1016/j.ifacol.2016.10.075.

Zhao T., Stark B., Chen Y., Ray A.L., Doll D. (2017) Challenges in Water Stress Quantification Using Small Unmanned Aerial System (sUAS): Lessons from a Growing Season of Almond. Journal of Intelligent \& Robotic Systems 88:721-735. DOI: 10.1007/s10846-017-0513-x.

This article is protected by copyright. All rights reserved. 


\section{List of Figures}

Figure 1. Examples of rotary-wing (A) and fixed-wing (B) UAV platforms: A. DJI Matrice 100, and B. Fixed wing customized UAV platform. Rotary-wing UAVs have Vertical Take-Off and Landing and Short Take-off and Landing capacities, ability to hover and fly in any direction, and the ability to fly at low speed, allowing easy control and maneuver. Fixed-wing, on the other hand, has rigid wings, which enables forward lifts. It has a simple structure, long flight range, and lower maintenance and repair costs. [Photo courtesy: Mr. Daniel Gonzalez, Texas AgriLife Research and Extension Center, Corpus Christi, Texas, US]

Figure 2. Examples of digital (A\&C), thermal (B), multi-spectral (D), and hyperspectral with LiDAR (E) sensors used in hydrology and water management. [Photo courtesy: Mr. Daniel Gonzalez, Texas AgriLife Research and Extension Center, Corpus Christi, Texas, US]

Figure 3. Example of UAV imaging payload for monitoring land surface evapotranspiration, soil moisture, carbon assimilation, and water use efficiency. The imaging part includes a RGB camera, a thermal infrared camera, and a multispectral camera. The navigation part can use either the post-processed kinematic (PPK) GNSS solution or the single receiver GNSS solution of Ublox. The micro-processor is the Beaglebone Black.

Figure 4. General UAV image processing workflow of RGB and multi-spectral images in agricultural water management. GPS: Ground Positioning System, RGB: Red, green, and white band. Raw images obtained from wheat breeding trial (Texas A\&M Wheat Breeding Program, Amarillo, US; Courtesy: Ms. Shannon Baker) were processed to generate DEMs.

This article is protected by copyright. All rights reserved. 


\section{List of Tables}

Table 1. Classification of UAVs (AGL= Above Ground Level; Adapted and modified from Qi et al. (2018))

Table 2. Hydrological application, advantages and disadvantages of different UAV sensors

Table 3. Some commonly used RGB sensors for UAVs with their main specifications

Table 4. Some commonly used multi-spectral sensors for UAVs with their main specifications

Table 5. Some commonly used hyperspectral sensors for UAVs with their main specifications

Table 6. Some commonly used thermal sensors for UAVs with their main specifications

Table 7. Some commonly used LiDAR sensors for UAVs with their main specifications

Table 8. Selected microwave sensors for UAVs with their main specification

Table 9. Selected vegetative indices and their hydrological application in agriculture and forestry

This article is protected by copyright. All rights reserved. 
Table 1

\begin{tabular}{|l|l|l|l|l|}
\hline Category & Weight $(\mathbf{k g})$ & $\begin{array}{l}\text { Altitude (ft } \\
\text { AGL) }\end{array}$ & Radius (km) & Endurance (h) \\
\hline Micro & $<2$ & Up to 200 & $<5$ & $<1$ \\
\hline Mini & $2-20$ & Up to 3000 & $<25$ & $1-2$ \\
\hline Small & $20-150$ & Up to 5000 & $<50$ & $1-5$ \\
\hline Tactical & $150-600$ & Up to 10,000 & $100-300$ & $4-15$ \\
\hline MALE & $>600$ & Up to 45,000 & $>500$ & $>24$ \\
\hline HALE & $>600$ & Up to 60,000 & Global & $>24$ \\
\hline
\end{tabular}

This article is protected by copyright. All rights reserved. 
Table 2

\begin{tabular}{|c|c|c|c|}
\hline Sensors & Hydrological application & Advantages & Disadvantages \\
\hline RGB & $\begin{array}{l}\text { Aerial photogrammetry, } \\
\text { DEM, bathymetry, flood } \\
\text { monitoring, surface flow } \\
\text { velocity, water quality, } \\
\text { snow and ice depth }\end{array}$ & $\begin{array}{l}\text { Portable, common, } \\
\text { relatively inexpensive, } \\
\text { provide high-quality RGB } \\
\text { images for orthoimagery } \\
\text { and DSM, easy to } \\
\text { integrate with different } \\
\text { platforms }\end{array}$ & $\begin{array}{l}\text { Wider bandwidth and } \\
\text { lower spectral resolution, } \\
\text { lack geometric and } \\
\text { radiometric calibration }\end{array}$ \\
\hline Multispectral & $\begin{array}{l}\text { Bathymetry, flood } \\
\text { monitoring, surface and } \\
\text { groundwater interaction, } \\
\text { water quality }\end{array}$ & $\begin{array}{l}\text { Multiple wavelengths, } \\
\text { allow geometric } \\
\text { reconstruction and } \\
\text { radiometric calibration }\end{array}$ & $\begin{array}{l}\text { Relatively costly, image } \\
\text { processing relatively } \\
\text { complex compared to } \\
\text { RGB, radiometric and } \\
\text { atmospheric } \\
\text { corrections may be } \\
\text { required, limited } \\
\text { compatibility to UAVs }\end{array}$ \\
\hline Hyperspectral & $\begin{array}{l}\text { Bathymetry, flood } \\
\text { monitoring, surface and } \\
\text { groundwater interaction, } \\
\text { hydrogeochemistry, } \\
\text { mapping rivers and } \\
\text { wetlands }\end{array}$ & $\begin{array}{l}\text { High spectral resolution } \\
\text { data across various } \\
\text { wavelength of VIS-NIR }\end{array}$ & $\begin{array}{l}\text { Higher cost than } \\
\text { multispectral, low signal- } \\
\text { to-noise ratio, limited } \\
\text { compatibility with standard } \\
\text { UAV and flight control } \\
\text { software packages, } \\
\text { radiometric and } \\
\text { atmospheric } \\
\text { corrections may be } \\
\text { required }\end{array}$ \\
\hline Microwave & $\begin{array}{l}\text { Flood monitoring, river } \\
\text { level and discharge, soil } \\
\text { moisture, altimetry, snow } \\
\text { water equivalent, snow } \\
\text { depth }\end{array}$ & $\begin{array}{l}\text { High spatial resolution, } \\
\text { useful under low visibility } \\
\text { weather conditions (e.g., } \\
\text { cloud cover) }\end{array}$ & $\begin{array}{l}\text { Sensitive to surface } \\
\text { roughness }\end{array}$ \\
\hline Thermal & $\begin{array}{l}\text { Temperature mapping, } \\
\text { tile drainage, } \\
\text { evapotranspiration, soil } \\
\text { moisture, turbidity } \\
\text { plumes, groundwater } \\
\text { discharge, wetland } \\
\text { mapping }\end{array}$ & $\begin{array}{l}\text { Sense a wide range of } \\
\text { temperatures, relatively } \\
\text { cheaper }\end{array}$ & $\begin{array}{l}\text { Thermally sensitive, } \\
\text { vignetting effects, low } \\
\text { spatial resolution, } \\
\text { radiometric corrections } \\
\text { required, sensitive to } \\
\text { change in surface } \\
\text { roughness }\end{array}$ \\
\hline LiDAR & $\begin{array}{l}\text { 3D reconstruction, } \\
\text { bathymetry, water surface } \\
\text { elevation, flood } \\
\text { monitoring, snow depth, } \\
\text { erosion, wetland mapping }\end{array}$ & $\begin{array}{l}\text { Generates dense cloud } \\
\text { points, high quality data, } \\
\text { direct geometric } \\
\text { measurements }\end{array}$ & $\begin{array}{l}\text { Higher cost, limited } \\
\text { compatibility with UAVs, } \\
\text { requires ground filtering } \\
\text { corrections }\end{array}$ \\
\hline
\end{tabular}

This article is protected by copyright. All rights reserved. 
Table 3

\begin{tabular}{|l|l|l|l|}
\hline $\begin{array}{l}\text { Model and } \\
\text { Manufacturer }\end{array}$ & Resolution & $\begin{array}{l}\text { Weight } \\
(\mathbf{g})\end{array}$ & $\begin{array}{l}\text { Dimension } \\
(\mathbf{m m})\end{array}$ \\
\hline Zenmuse X7 DJI & $24.0 \mathrm{MP}$ & 449.0 & $151 \times 108 \times 132$ \\
\hline Zenmuse X5S DJI & $20.8 \mathrm{MP}$ & 461.0 & $140 \times 98 \times 132$ \\
\hline Zenmuse X4S DJI & $20.0 \mathrm{MP}$ & 253.0 & $125 \times 100 \times 80$ \\
\hline $\begin{array}{l}\text { Canon PowerShot } \\
\text { S100 }\end{array}$ & $12.1 \mathrm{MP}$ & 193.2 & $\begin{array}{l}98.9 \times 59.9 \times \\
26.7\end{array}$ \\
\hline senseFly Corridor & $5472 \times 3648 \mathrm{Px}$ & 111.0 & - \\
\hline
\end{tabular}

This article is protected by copyright. All rights reserved. 
Table 4

\begin{tabular}{|c|c|c|c|c|c|c|}
\hline $\begin{array}{l}\text { Model and } \\
\text { Manufacturer }\end{array}$ & Dimension & Resolution & $\begin{array}{l}\text { Weight } \\
\text { (g) }\end{array}$ & $\begin{array}{l}\text { Central } \\
\text { waveband } \\
(\mathbf{n m})\end{array}$ & $\begin{array}{l}\text { Spectral } \\
\text { range } \\
(\mathbf{n m})\end{array}$ & $\begin{array}{l}\text { Field of } \\
\text { View }\left({ }^{0}\right)\end{array}$ \\
\hline $\begin{array}{l}\text { RedEdge-MX } \\
\text { MicaSense }\end{array}$ & $\begin{array}{l}8.7 \mathrm{~cm} \times 5.9 \\
\mathrm{~cm} \times 4.54 \\
\mathrm{~cm}\end{array}$ & $\begin{array}{l}1280 \times 960 \\
P x\end{array}$ & 231.9 & $\begin{array}{l}\text { Blue: } 475 \\
\text { Green: } 560 \\
\text { Red: } 668 \\
\text { Red edge: } \\
717 \\
\text { NIR: } 842\end{array}$ & $\begin{array}{l}443-507 \\
533-587 \\
554-682 \\
705-729 \\
885-899\end{array}$ & 47.2 \\
\hline $\begin{array}{l}\text { SlantRange } \\
4 \mathrm{P}+ \\
\text { SlantRange }\end{array}$ & $\begin{array}{l}14.6 \times 6.9 \times \\
5.7 \mathrm{~cm}\end{array}$ & - & 350 & $\begin{array}{l}\text { Blue: } 470 \\
\text { Green: } 520 \\
\text { Red: } 620 \\
\text { Red: } 650 \\
\text { Red edge: } \\
715 \\
\text { NIR: } 850\end{array}$ & $410-950$ & - \\
\hline $\begin{array}{l}6 \mathrm{XX} \\
\text { Multispectral } \\
\text { sensor } \\
\text { Sentera }\end{array}$ & $\begin{array}{l}79 \mathrm{~mm} \times 66 \\
\mathrm{~mm} \times 67 \\
\mathrm{~mm}\end{array}$ & $\begin{array}{l}\text { RGB } \\
\text { imager: } 20 \\
\text { MP } \\
\text { Global } \\
\text { shutter } \\
\text { imager: } 3.2 \\
\text { MP }\end{array}$ & 280 & $\begin{array}{l}\text { Blue: } 475 \\
\text { Green: } 550 \\
\text { Red: } 670 \\
\text { Red edge: } \\
715 \\
\text { NIR: } 840\end{array}$ & $\begin{array}{l}445-505 \\
530-570 \\
640-700 \\
705-725 \\
820-860\end{array}$ & 47 \\
\hline $\begin{array}{l}\text { P4 multi- } \\
\text { spectral } \\
\text { DJI } \\
\text { (Attached to } \\
\text { aircraft) }\end{array}$ & - & $2.12 \mathrm{MP}$ & - & $\begin{array}{l}\text { Blue: } 450 \\
\text { Green: } 560 \\
\text { Red: } 650 \\
\text { Red edge: } \\
730 \\
\text { NIR: } 840\end{array}$ & $\begin{array}{l}434-466 \\
544-576 \\
6634-666 \\
714-746 \\
822-858\end{array}$ & 62.7 \\
\hline $\begin{array}{l}\text { Parrot } \\
\text { Sequoia+ }\end{array}$ & - & $1.2 \mathrm{MP}$ & - & $\begin{array}{l}\text { Green: } 550 \\
\text { Red: } 660 \\
\text { Red edge: } \\
735 \\
\text { NIR: } 790\end{array}$ & $\begin{array}{l}510-590 \\
620-700 \\
725-745 \\
750-840\end{array}$ & $\begin{array}{l}\text { HFOV: } \\
62 \\
\text { VFOV: } \\
49 \\
\text { DFOV: } \\
74\end{array}$ \\
\hline Sentra Quad & $\begin{array}{l}76 \mathrm{~mm} \times 62 \\
\mathrm{~mm} \times 48 \\
\mathrm{~mm}\end{array}$ & $1.2 \mathrm{MP}$ & - & $\begin{array}{l}\text { Red: } 655 \\
\text { Red edge: } \\
725 \\
\text { NIR: } 800\end{array}$ & $\begin{array}{l}615-695 \\
700-750 \\
775-525\end{array}$ & $\begin{array}{l}\text { HFOV: } \\
50 \\
\text { VFOV: } \\
39\end{array}$ \\
\hline
\end{tabular}

This article is protected by copyright. All rights reserved. 
Table 5

\begin{tabular}{|l|l|l|l|l|}
\hline $\begin{array}{l}\text { Model and } \\
\text { Manufacturer }\end{array}$ & $\begin{array}{l}\text { Weight } \\
(\mathbf{g})\end{array}$ & $\begin{array}{l}\text { Spectral } \\
\text { range }(\mathbf{n m})\end{array}$ & $\begin{array}{l}\text { Number of } \\
\text { bands }\end{array}$ & $\begin{array}{l}\text { Spatial } \\
\text { resolution (Px) }\end{array}$ \\
\hline $\begin{array}{l}\text { Rikola Hyperspectral } \\
\text { camera }\end{array}$ & 700 & $500-900$ & 24 & $1024 \times 1024$ \\
\hline HySpex Mjolnir V-1240 & 4000 & $400-1000$ & - & 1240 \\
\hline HySpex Mjolnir S-620 & 4500 & $970-2500$ & - & 620 \\
\hline ULTRIS 20 Plus Cube & 630 & $450-850$ & 106 & $1880 \times 1880$ \\
\hline ULTRIS 20 Cube & 350 & $450-850$ & 100 & - \\
\hline FireflEYE 185 Cube & 490 & $450-950$ & 125 & $1000 \times 1000$ \\
\hline FireflEYE 496 blue Cube & 1200 & $370-870$ & 125 & $1600 \times 1600$ \\
\hline BaySpec OCI-UAV-1000 & 180 & $600-1000$ & 100 & $2048 \times 2048$ \\
\hline $\begin{array}{l}\text { Brandywine Photonics } \\
\text { CHAI V-640 }\end{array}$ & 480 & $350-1080$ & 256 & $640 \times 512$ \\
\hline Quest Hyperea 660 C1 & 1440 & $400-1000$ & 660 & $1024 \times 1024$ \\
\hline $\begin{array}{l}\text { NovaSol Alpha-SWIR } \\
\text { micro HSI }\end{array}$ & 1200 & $99-1700$ & 160 & $640 \times 640$ \\
\hline $\begin{array}{l}\text { SENOP VIS-VNIR } \\
\text { Snapshot }\end{array}$ & 720 & $400-900$ & 380 & $1010 \times 1010$ \\
\hline HySpex VNIR-1024 & 4000 & $400-1000$ & 108 & $1024 \times 1024$ \\
\hline
\end{tabular}

This article is protected by copyright. All rights reserved. 
Table 6

\begin{tabular}{|l|l|l|l|l|}
\hline $\begin{array}{l}\text { Model and } \\
\text { Manufacturer }\end{array}$ & $\begin{array}{l}\text { Sensor } \\
\text { resolution }(\mathbf{P x})\end{array}$ & Weight $(\mathbf{g})$ & $\begin{array}{l}\text { Spectral band } \\
(\boldsymbol{\mu m})\end{array}$ & $\begin{array}{l}\text { Dimensions } \\
(\mathbf{m m})\end{array}$ \\
\hline $\begin{array}{l}\text { Zenmuse XT, } \\
\text { FLIR \& DJI }\end{array}$ & - & 270 & $7.5-13.5$ & $103 \times 74 \times 102$ \\
\hline FLIR Vue Pro R & $\begin{array}{l}640 \times 512 / 336 \times \\
256\end{array}$ & $92-113$ & $7.5-13.5$ & $\begin{array}{l}57.40 \times 44.45 \\
\mathrm{~mm}\end{array}$ \\
\hline FLIR Duo Pro R & $336 \times 256$ & 325 & $7.5-13.5$ & $85 \times 81.3 \times 68.5$ \\
\hline $\begin{array}{l}\text { FLIR Boson } \\
\text { LWIR }\end{array}$ & $\begin{array}{l}640 \times 512 / 320 \times \\
256\end{array}$ & $\begin{array}{l}7.5(\text { without } \\
\text { lens) }\end{array}$ & $7.5-13.5$ & $74 \times 46 \times 61$ \\
\hline Optris PI400i & $382 \times 288$ & $\begin{array}{l}237-251 \text { (based } \\
\text { on lens) }\end{array}$ & $8-14$ & - \\
\hline
\end{tabular}

This article is protected by copyright. All rights reserved. 
Table 7

\begin{tabular}{|c|c|c|c|c|c|c|}
\hline $\begin{array}{l}\text { Model and } \\
\text { Manufacturer }\end{array}$ & $\begin{array}{l}\text { Weight } \\
\text { (g) }\end{array}$ & $\begin{array}{l}\text { Dimension } \\
(\mathrm{mm})\end{array}$ & $\begin{array}{l}\text { Wavelength } \\
(\mathrm{nm})\end{array}$ & $\begin{array}{l}\text { FOV } \\
\left({ }^{0}\right)\end{array}$ & $\begin{array}{l}\text { Measurement } \\
\text { rate (points } \\
\text { second) }\end{array}$ & $\begin{array}{l}\text { Vertical } \\
\text { accuracy } \\
(\mathbf{m m})^{1}\end{array}$ \\
\hline $\begin{array}{l}\text { RTL-400 } \\
\text { Redtail LiDar } \\
\text { Systems }\end{array}$ & 453.5 & $\begin{array}{l}154.94 \times \\
154.94 \times \\
195.58\end{array}$ & 1550 & $\begin{array}{l}\mathrm{H}=40 \\
\mathrm{~V}=40\end{array}$ & 1 million & 20 \\
\hline $\begin{array}{l}\text { HDL-32E } \\
\text { Velodyne Lidar }\end{array}$ & 1000 & $\begin{array}{l}\text { Height }=144 \\
\text { Diameter } \\
=86.36\end{array}$ & & $\begin{array}{l}\mathrm{H}=360 \\
\mathrm{~V}=+10- \\
-30\end{array}$ & 1.39 million & 15 \\
\hline $\begin{array}{l}\text { Puck LITE } \\
\text { Velodyne }\end{array}$ & 590 & --- & --- & $\begin{array}{l}H=360 \\
V= \pm 15\end{array}$ & 300,000 & --- \\
\hline $\begin{array}{l}\text { VUX-1UAV } \\
\text { Riegl USA }\end{array}$ & 3500 & $\begin{array}{l}227 \times 180 \times \\
125\end{array}$ & & 330 & 500,000 & 10 \\
\hline $\begin{array}{l}\text { Surveyor } \\
\text { YellosScan }\end{array}$ & 1600 & - & & 260 & - & 50 \\
\hline $\begin{array}{l}\text { Bathymetric } \\
\text { LiDAR } \\
\text { ASTRALiTe } \\
\text { EDGE }\end{array}$ & 5000 & $\begin{array}{l}270 \times 230 \times \\
190\end{array}$ & 532 & 30 & 20000 & 10 \\
\hline $\begin{array}{l}\text { Bathymetric } \\
\text { LiDAR RIEGL } \\
\text { BDF-1 }\end{array}$ & 5300 & $\begin{array}{l}140 \times \\
179 \times \\
448\end{array}$ & 532 & $\begin{array}{l}\text { Single } \\
\text { laser } \\
\text { (profili } \\
\text { ng } \\
\text { instrum } \\
\text { ent) }\end{array}$ & 4000 & 20 \\
\hline $\begin{array}{l}\text { Bathymetric } \\
\text { LiDAR Amuse } \\
\text { Oneself TDOT } \\
\text { GREEN }\end{array}$ & 2600 & $\begin{array}{l}260 \times \\
220 \times \\
150\end{array}$ & 532 & 90 & 60000 & $\begin{array}{l}15 \mathrm{~mm} \text { at } \\
\geqq 10 \% \\
\text { bottom } \\
\text { reflectivity }\end{array}$ \\
\hline $\begin{array}{l}\text { Bathymetric } \\
\text { LiDAR } \\
\text { Fugro RAMMS }\end{array}$ & 14000 & $\begin{array}{l}407 \times \\
407 \times \\
700\end{array}$ & 532 & $\begin{array}{l}\text { Linear } \\
\text { pushbro } \\
\text { om }+15 \\
\text { backwa } \\
\text { rd }\end{array}$ & 27000 & $\begin{array}{l}\text { Reported } \\
\text { by the } \\
\text { manufactur } \\
\text { er as } \\
\text { function of } \\
\text { depth }\end{array}$ \\
\hline
\end{tabular}

Horizontal $=\mathrm{H}$, Vertical $=\mathrm{V}$

${ }^{1}$ This is the accuracy as reported by the manufacturer, and typically refers to LiDAR only, without including GNSS and IMU. Accuracy values should be taken with caution, especially for bathymetry LiDAR.

This article is protected by copyright. All rights reserved. 
Table 8

\begin{tabular}{|c|c|c|c|c|c|c|}
\hline $\begin{array}{l}\text { Model and } \\
\text { Manufacturer }\end{array}$ & Technology & $\begin{array}{l}\text { Weight } \\
\text { (g) }\end{array}$ & $\begin{array}{l}\text { Dimensions } \\
(\mathrm{mm})\end{array}$ & Frequency & Bandwidth & Beamwidth \\
\hline Ariel-Balamis & $\begin{array}{l}\text { Passive } \\
\text { microwave } \\
\text { (GNSS- } \\
\text { reflectometer) }\end{array}$ & 2800 & Unknown & $\begin{array}{l}1413 \mathrm{MHz} \\
\text { (L-band) }\end{array}$ & $20 \mathrm{MHz}$ & $37^{\circ}$ \\
\hline $\begin{array}{l}\text { Black Swift } \\
\text { Technologies } \\
\text { L-band } \\
\text { radiometer }\end{array}$ & $\begin{array}{l}\text { Passive } \\
\text { microwave } \\
\text { (GNSS- } \\
\text { reflectometer) }\end{array}$ & $1000^{1}$ & $\begin{array}{l}200 \times 200 \times \\
600^{1}\end{array}$ & L-band & Unreported & Unreported \\
\hline $\begin{array}{l}\text { Malå80 } \\
\text { Guideline Geo }\end{array}$ & GPR & 3230 & $\begin{array}{l}580 \times 1040 \\
\times 240\end{array}$ & $80 \mathrm{MHz}$ & Unreported & Unknown \\
\hline $\begin{array}{l}\text { Gekko-80 } \\
\text { Geoscanners }\end{array}$ & GPR & $\begin{array}{l}3300 \\
\text { (antenna) } \\
+1000 \\
\text { (processin } \\
\text { g unit } \\
\text { RTS- } \\
1600 \text { ) } \\
\end{array}$ & $\begin{array}{l}1375 \times 120 \\
\times 222\end{array}$ & $80 \mathrm{MHz}$ & $\begin{array}{l}\text { Ca. } 110 \\
\mathrm{MHz}\end{array}$ & Unknown \\
\hline $\begin{array}{l}\text { Gekko-120 } \\
\text { Geoscanners }\end{array}$ & GPR & $\begin{array}{l}2500 \\
\text { (antenna) } \\
+1000 \\
\text { (processin } \\
\text { g unit } \\
\text { RTS- } \\
1600 \text { ) } \\
\end{array}$ & $\begin{array}{l}800 \times 120 \times \\
222\end{array}$ & $120 \mathrm{MHz}$ & $\begin{array}{l}\text { Ca. } 170 \\
\mathrm{MHz}\end{array}$ & Unknown \\
\hline $\begin{array}{l}\text { SPG series- } \\
\text { Geoscanners } \\
\text { (e.g. SPG } \\
1800,1600 \text {, } \\
\text { 1700A, 1700, } \\
\text { etc.) }\end{array}$ & GPR & $\begin{array}{l}\text { Dependin } \\
\mathrm{g} \text { on the } \\
\text { product }\end{array}$ & $\begin{array}{l}\text { Depending } \\
\text { on the } \\
\text { product }\end{array}$ & $\begin{array}{l}\text { Depending } \\
\text { on the } \\
\text { product } \\
\text { (e.g. } 390 \text {, } \\
500,600 \text {, } \\
1200 \mathrm{MHz} \text { ) }\end{array}$ & $\begin{array}{l}\text { Depending } \\
\text { on the } \\
\text { product }\end{array}$ & Unknown \\
\hline $\begin{array}{l}\text { Cobra Plug-in } \\
\text { SE-40 } \\
\text { Radarteam } \\
\end{array}$ & GPR & 4700 & $\begin{array}{l}2000 \times 150 \\
\times 210\end{array}$ & $52 \mathrm{MHz}$ & $90 \mathrm{MHz}$ & Unknown \\
\hline $\begin{array}{l}\text { Cobra Plug-in } \\
\text { SE-70 } \\
\text { Radarteam }\end{array}$ & GPR & 3700 & $\begin{array}{l}1390 \times 150 \\
\times 210\end{array}$ & $80 \mathrm{MHz}$ & $120 \mathrm{MHz}$ & Unknown \\
\hline $\begin{array}{l}\text { Cobra Plug-in } \\
\text { SE-150 } \\
\text { Radarteam }\end{array}$ & GPR & 3500 & $\begin{array}{l}920 \times 220 \times \\
220\end{array}$ & $124 \mathrm{MHz}$ & $260 \mathrm{MHz}$ & Unknown \\
\hline
\end{tabular}

1 (including all front-end electronics, antenna, and thermal and multispectral sensors)

This article is protected by copyright. All rights reserved. 
Table 9

\begin{tabular}{|c|c|c|c|}
\hline Indices & Equation & Use & References \\
\hline $\begin{array}{l}\text { Normalized Difference } \\
\text { Vegetation Index, NDVI }\end{array}$ & $\frac{N I R-R}{N I R+R}$ & Crop monitoring & (Jackson et al., 1980) \\
\hline $\begin{array}{l}\text { Wide Dynamic Range } \\
\text { Vegetation Index, } \\
\text { WDRVI }\end{array}$ & $\frac{a * N I R-R}{a * N I R+R}(0<\mathrm{a}<1)$ & Crop monitoring & (Gitelson, 2004) \\
\hline $\begin{array}{l}\text { Renormalized Difference } \\
\text { Vegetation Index, RDVI }\end{array}$ & $\frac{R 800-R 670}{(R 800+R 670)^{\wedge} 0.5}$ & Crop monitoring & $\begin{array}{c}\text { (Roujean and Breon, } \\
1995)\end{array}$ \\
\hline $\begin{array}{l}\text { Optimized Soil Adjusted } \\
\text { Vegetation Index, OSAVI }\end{array}$ & $\frac{(1+0.16)(R 800-R 670)}{(R 800+R 670+0.16)}$ & $\begin{array}{l}\text { Soil color, } \\
\text { moisture }\end{array}$ & $\begin{array}{c}\text { (Rondeaux et al., } \\
1996)\end{array}$ \\
\hline $\begin{array}{c}\text { Enhanced Vegetation } \\
\text { Index, EVI }\end{array}$ & $2.5^{*}\left(\frac{N I R-R}{N I R+(6 * R)-(7.5 * B)+1}\right)$ & Crop monitoring & (Jiang et al., 2008) \\
\hline $\begin{array}{c}\text { Moisture Stress Index, } \\
\text { MSI }\end{array}$ & $\frac{R 1600}{R 820}$ & $\begin{array}{c}\text { Canopy water } \\
\text { content }\end{array}$ & (Hunt et al., 2005) \\
\hline $\begin{array}{l}\text { Normalized Difference } \\
\text { Water Index, NDWI }\end{array}$ & $\frac{R 860-R 1240}{R 860+R 1240}$ & $\begin{array}{l}\text { Canopy water } \\
\text { content }\end{array}$ & $\begin{array}{l}\text { (Stimson et al., } \\
\text { 2005) }\end{array}$ \\
\hline $\begin{array}{l}\text { Normalized Difference } \\
\text { Infrared Index, NDII }\end{array}$ & $\frac{R 820-R 1600}{R 820+R 1600}$ & $\begin{array}{l}\text { Canopy water } \\
\text { content }\end{array}$ & $\begin{array}{c}\text { (Hardisky et al., } \\
1983 \text { ) }\end{array}$ \\
\hline $\begin{array}{l}\text { Maximum Difference } \\
\text { Water Index, MDWI }\end{array}$ & $\frac{R \max -R \min }{R \max +R \min }$ & $\begin{array}{c}\text { Canopy water } \\
\text { content }\end{array}$ & (Eitel et al., 2006) \\
\hline $\begin{array}{l}\text { Soil Adjusted Vegetation } \\
\text { Index, SAVI }\end{array}$ & $\left(\frac{N I R-R}{N I R+R}\right) *(1+\mathrm{L})$ & $\begin{array}{l}\text { Soil color, } \\
\text { moisture, } \\
\text { background } \\
\text { variability }\end{array}$ & (Qi et al., 1994) \\
\hline
\end{tabular}

Note: Some vegetation indices recently used in precision agriculture are available from Sishodia et al. (2020)

This article is protected by copyright. All rights reserved. 

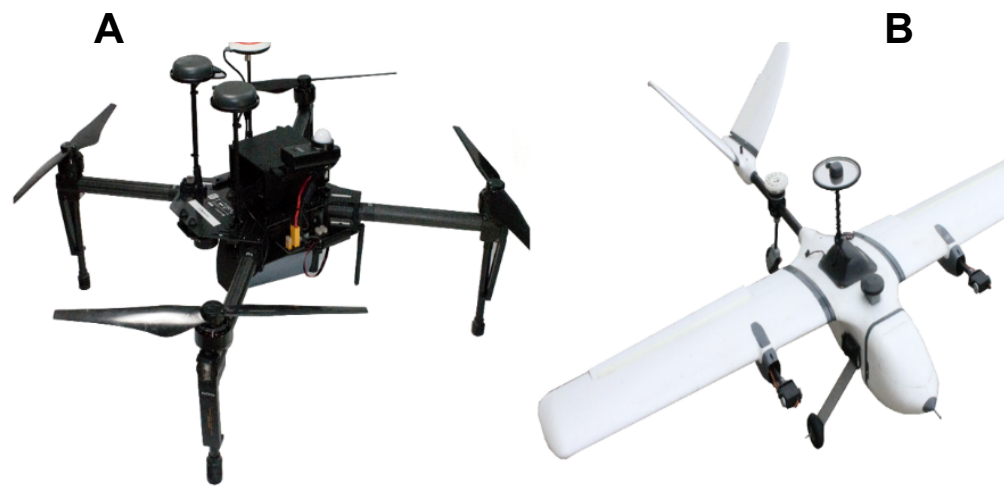

This article is protected by copyright. All rights reserved. 


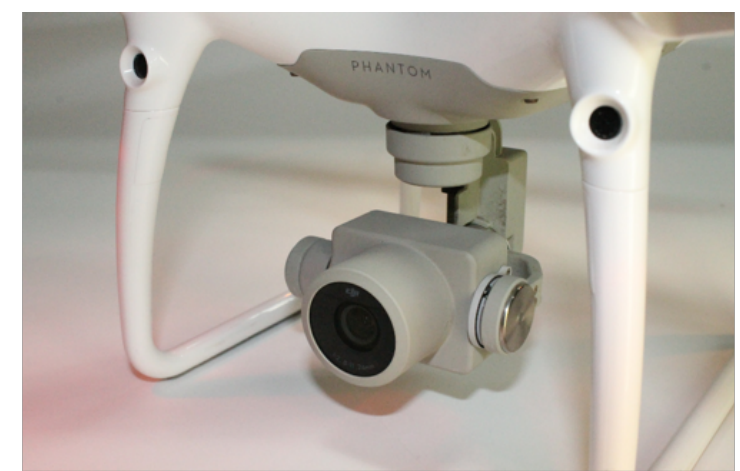

A

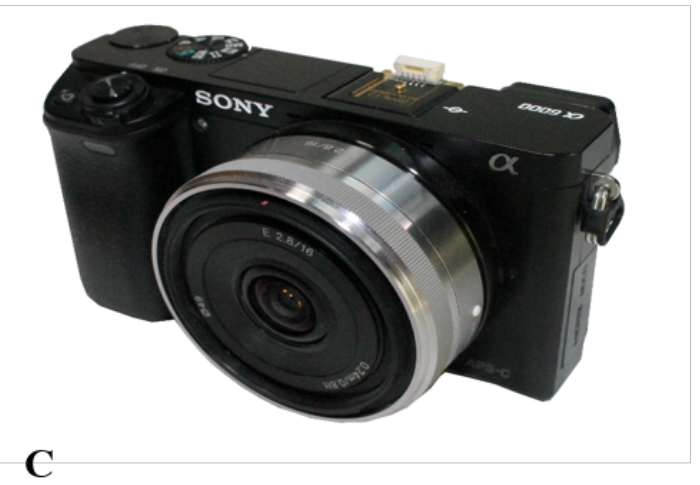

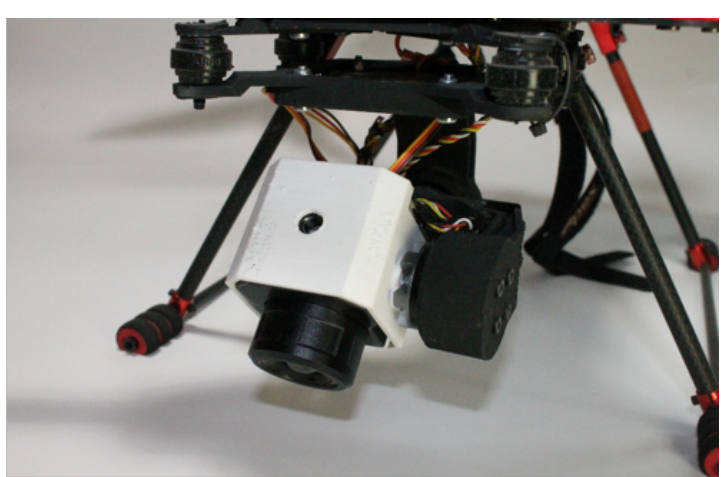

B

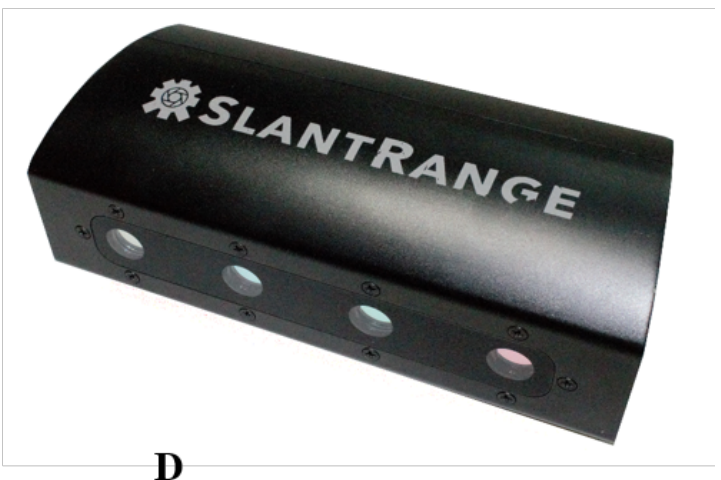

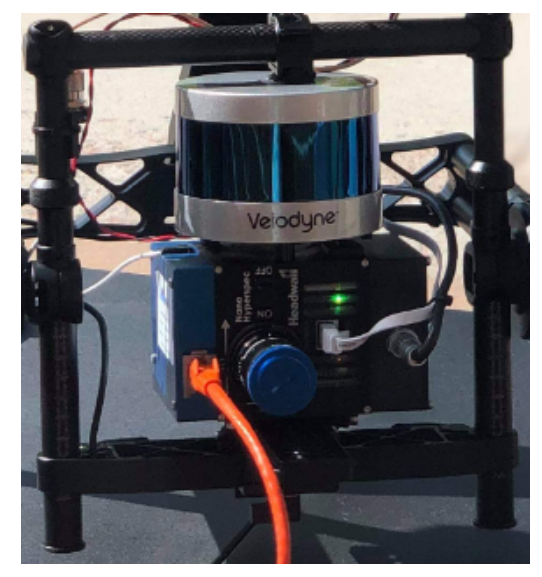

E

This article is protected by copyright. All rights reserved. 


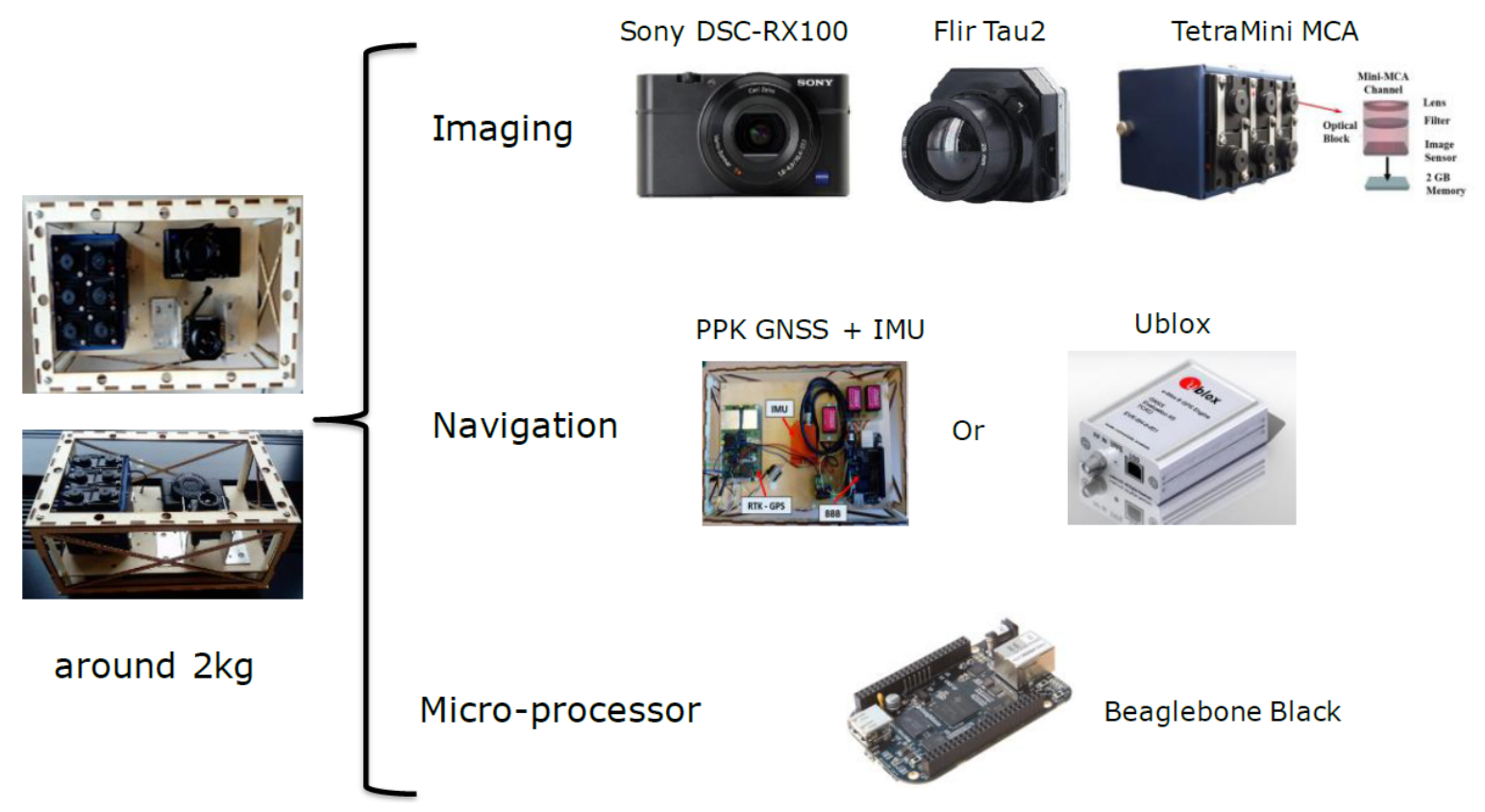

This article is protected by copyright. All rights reserved. 


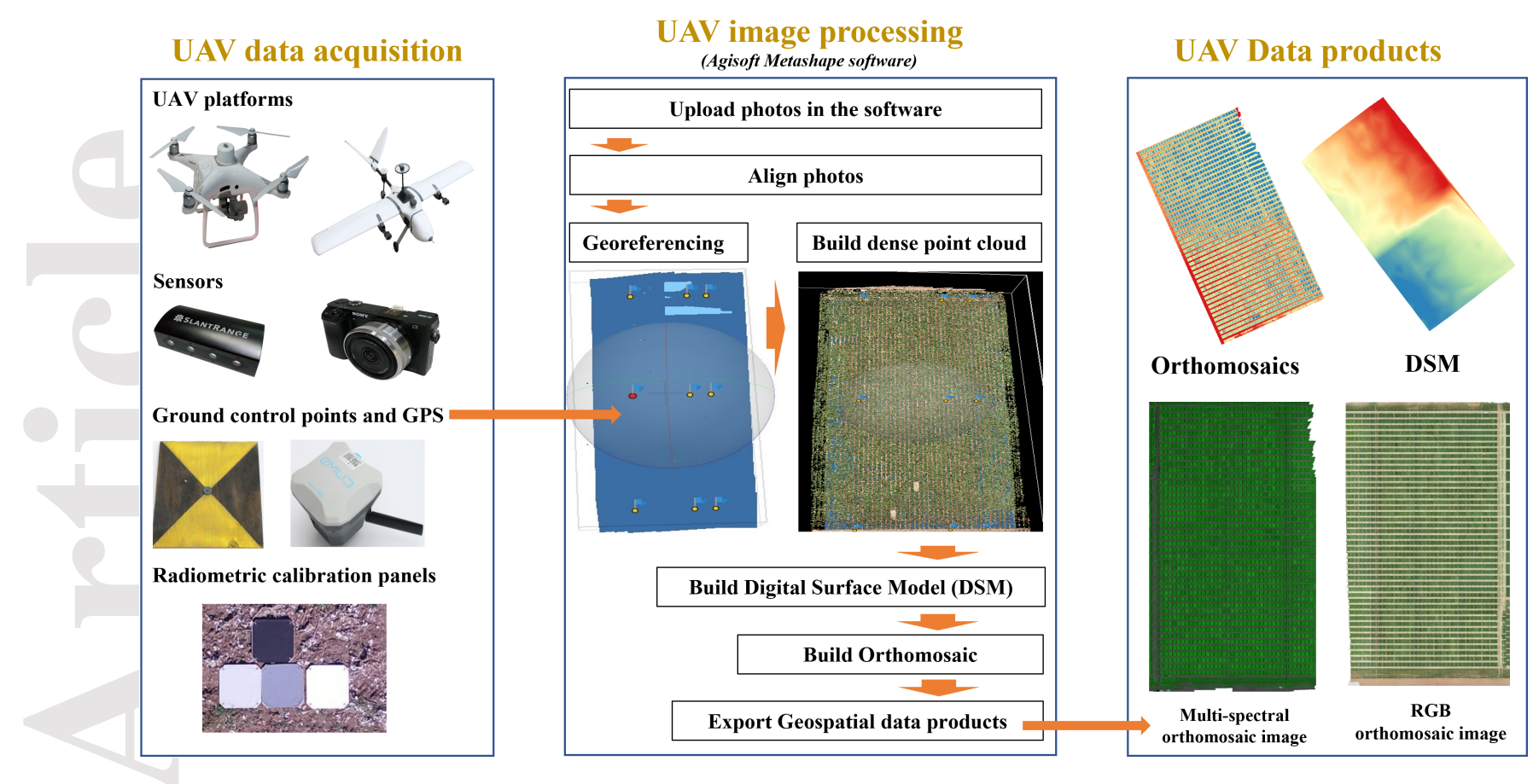

This article is protected by copyright. All rights reserved. 